\title{
Modeling and Mutational Analysis of the Binding Mode for the Multimodal Antidepressant Drug Vortioxetine to the Human $5-\mathrm{HT}_{3 \mathrm{~A}}$ Receptor ${ }^{\circledR}$
}

\author{
Lucy Kate Ladefoged, Lachlan Munro, Anders J. Pedersen, Sarah C. R. Lummis, \\ Benny Bang-Andersen, Thomas Balle, Birgit Schiøtt, and Anders S. Kristensen
}

Interdisciplinary Nanoscience Center, Department of Chemistry, Aarhus University, Aarhus, Denmark (L.K.L., B.S.); Department of Drug Design and Pharmacology, University of Copenhagen, Copenhagen, Denmark (L.M., A.J.P., A.S.K.); Department of Biochemistry, University of Cambridge, Cambridge, United Kingdom (S.C.R.L.); Lundbeck Research, H. Lundbeck A/S, Valby, Denmark (B.B.-A.); and Sydney School of Pharmacy, Faculty of Medicine and Health, The University of Sydney, Sydney, New South Wales, Australia (T.B.)

Received July 20, 2018; accepted September 19, 2018

\section{ABSTRACT}

5-Hydroxytryptamine $3\left(5-\mathrm{HT}_{3}\right)$ receptors are ligand-gated ion channels that mediate neurotransmission by serotonin in the central nervous system. Pharmacological inhibition of $5-\mathrm{HT}_{3}$ receptor activity has therapeutic potential in several psychiatric diseases, including depression and anxiety. The recently approved multimodal antidepressant vortioxetine has potent inhibitory activity at $5-\mathrm{HT}_{3}$ receptors. Vortioxetine has an inhibitory mechanism that differs from classic $5-\mathrm{HT}_{3}$ receptor competitive antagonists despite being believed to bind in the same binding site. Specifically, vortioxetine shows partial agonist activity followed by persistent and insurmountable inhibition. We have investigated the binding mode of vortioxetine at the human $5-\mathrm{HT}_{3 \mathrm{~A}}$ receptor through computational and in vitro experiments to provide insight into the molecular mechanisms behind the unique pharmacological profile of the drug. We find that vortioxetine binds in a manner different from currently known $5-\mathrm{HT}_{3 \mathrm{~A}}$ orthosteric ligands. Specifically, while the binding pattern of vortioxetine mimics some aspects of both the setron class of competitive antagonists and 5-hydroxytryptamine (5-HT) with regards to interactions with residues of the aromatic box motif in the orthosteric binding site, vortioxetine also forms interactions with residues not previously described to be important for the binding of either setrons or 5-HT such as Val202 on Loop F. Our results expand the framework for understanding how orthosteric ligands drive $5-\mathrm{HT}_{3}$ receptor function, which is of importance for the potential future development of novel classes of $5-\mathrm{HT}_{3}$ receptor antagonists.

\section{Introduction}

Serotonin [5-hydroxytryptamine (5-HT)] is a neurotransmitter that via ionotropic $5-\mathrm{HT}_{3}$ receptors, and a range of metabotropic receptors, regulates neural activities underlying a wide spectrum of basal as well as higher brain functions, including appetite, aggression, sleep, mood, and cognition (Berger et al., 2009). 5- $\mathrm{HT}_{3}$ receptors belong to the pentameric ligand-gated ion channel (pLGIC) superfamily together with structurally and functionally related nicotinic acetylcholine receptors, $\mathrm{GABA}_{\mathrm{A}}$ receptors, and glycine receptors (GlyRs)

B.B.-A. is an employee of H. Lundbeck A/S

This work was supported by the Danish Council of Independent Research for Medical Sciences [Grant DFF-404-00309]; the Lundbeck Foundation [Grants 2017-1655 and 2012-12453]; and the Carlsberg Foundation. Computations were made possible through allocations at the Centre for Scientific Computing, Arhus.

https://doi.org/10.1124/mol.118.113530.

S This article has supplemental material available at molpharm. aspetjournals.org.
(Barnes et al., 2009; Lummis, 2012; Nys et al., 2013; Nemecz et al., 2016). 5- $\mathrm{HT}_{3}$ receptor inhibitors are in current use as antiemetics and for the treatment of irritable bowel syndrome and are considered a potential therapy for anxiety-related behavior and cognitive decline in major depressive disorder and schizophrenia (Robertson et al., 1992; Thompson et al., 2006b).

Vortioxetine (Fig. 1C) is a multimodal antidepressant that acts as an inhibitor at the serotonin transporter, an agonist at $5-\mathrm{HT}_{1 \mathrm{~A}}$ receptors, a partial agonist at $5-\mathrm{HT}_{1 \mathrm{~B}}$ receptors, and an antagonist at $5-\mathrm{HT}_{1 \mathrm{D}}, 5-\mathrm{HT}_{3}$, and $5-\mathrm{HT}_{7}$ receptors (BangAndersen et al., 2011; Sanchez et al., 2015). In addition to antidepressive effects, vortioxetine has been shown to improve aspects of cognitive function such as attention, processing speed, executive function, and memory (McIntyre et al., 2014, 2017; Mahableshwarkar et al., 2015), which may be linked to activity at 5- $\mathrm{HT}_{3}$ receptors (Mørk et al., 2013; Riga et al., 2016).

The molecular understanding of vortioxetine inhibition of $5-\mathrm{HT}_{3}$ receptors is currently limited. Vortioxetine is suggested to bind at the orthosteric binding site in $5-\mathrm{HT}_{3 \mathrm{~A}}$ receptors but

ABBREVIATIONS: 5-HT, 5-hydroxytryptamine (serotonin); 5-HTBP, 5-hydroxytryptamine binding protein; ECD, extracellular domain; GlyR, glycine receptor; HEK-293, human embryonic kidney 293; h5-HT 3 , human 5-hydroxytryptamine $3 \mathrm{~A}$; hSERT, human serotonin transporter; IFD, induced fit docking; m5- $\mathrm{HT}_{3 \mathrm{~A}}$, mouse 5- $\mathrm{HT}_{3 \mathrm{~A}}$; MD, molecular dynamics; MM-PBSA, molecular mechanics-Poisson-Boltzmann and surface area; pLGIC, pentameric ligand-gated ion channel; WT, wild type. 


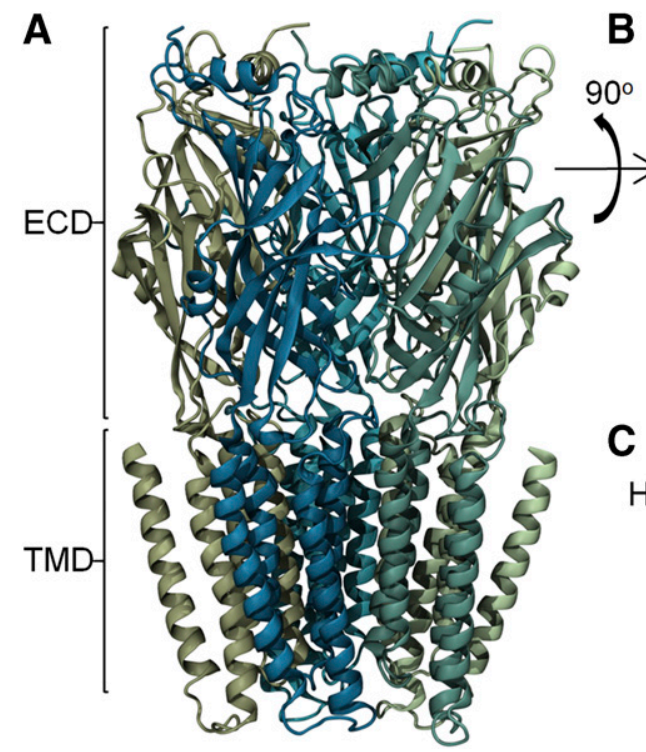

Fig. 1. Structural model of the $\mathrm{h} 5-\mathrm{HT}_{3 \mathrm{~A}}$ receptor and chemical structure of vortioxetine. Side (A) and top (B) views of ribbon representations of the $\mathrm{h} 5-\mathrm{HT}_{3 \mathrm{~A}}$ receptor structure created by homology modeling. Each subunit in the pentameric complex is colored individually. Brackets indicate the location of the ECD and transmembrane domain (TMD). (C) Chemical structure of vortioxetine with an indication of the $\mathrm{A}$ and $\mathrm{B}$ ring nomenclature. differs in mechanism from other $5-\mathrm{HT}_{3}$ antagonists by having an initial partial agonistic response followed by an apparently insurmountable inhibition of receptor function (BangAndersen et al., 2011; Dale et al., 2018). Thus, vortioxetine acts as a functional antagonist under steady-state conditions, although likely through a different mechanism to that of classic competitive $5-\mathrm{HT}_{3}$ antagonists (collectively known as setrons). The orthosteric binding site of $5-\mathrm{HT}_{3}$ receptors is formed at the interface between subunits in the extracellular domain (ECD) (Nys et al., 2013; Hassaine et al., 2014; Nemecz et al., 2016). As pentamers, five potential agonist binding sites exist in the $5-\mathrm{HT}_{3}$ receptor. Occupancy of one or two sites appear sufficient to drive conformational ECD rearrangements that trigger channel opening and subsequent entry to a desensitized conformation (Corradi et al., 2009; Rayes et al., 2009; Hibbs and Gouaux, 2011; Andersen et al., 2013). Cryo-electron microscopy and X-ray crystal structures are available for eukaryotic pLGICs (Unwin, 2005; Hibbs and Gouaux, 2011; Unwin and Fujiyoshi, 2012; Zuber and Unwin, 2013; Althoff et al., 2014; Miller and Aricescu, 2014; Du et al., 2015; Huang et al., 2015, 2017; Morales-Perez et al., 2016), including two structures of the mouse 5- $\mathrm{HT}_{3 \mathrm{~A}}\left(\mathrm{~m} 5-\mathrm{HT}_{3 \mathrm{~A}}\right)$ receptor (Hassaine et al., 2014; Basak et al., 2018). Furthermore, AChBP (Smit et al., 2001), a soluble eukaryotic protein that forms pentamers with an overall tertiary fold similar to the ECD of pLGICs (Brejc et al., 2001), has been engineered to acquire a $5-\mathrm{HT}_{3}$ receptor-like ligand profile (Kesters et al., 2013). This construct, denoted as the 5-HT binding protein (5-HTBP), allows for crystallographic analysis of $5-\mathrm{HT}_{3}$ receptor ligand binding (Kesters et al., 2013; Price et al., 2015, 2016). Combined with computational, mutational, and biochemical analysis, structures provide insight into the molecular architecture of the 5- $\mathrm{HT}_{3}$ receptor orthosteric binding site (Kesters et al., 2013; Hassaine et al., 2014) and ligand binding modes (Joshi et al., 2006; Moura Barbosa et al., 2010; Kesters et al., 2013; Price et al., 2015, 2016; Lochner and Thompson, 2016), and the potential conformational changes associated with ligand binding (Miller and Smart, 2010; Sander et al., 2010). From this and other work, a framework is emerging for understanding the molecular basis that underlies $5-\mathrm{HT}_{3}$ agonism and antagonism (Nys et al., 2013; Alix et al., 2016).

In the present study, we have studied the molecular basis of vortioxetine inhibition of human $5-\mathrm{HT}_{3 \mathrm{~A}}\left(\mathrm{~h} 5-\mathrm{HT}_{3 \mathrm{~A}}\right)$ receptors by constructing a structural model of h5-HT $\mathrm{H}_{3 \mathrm{~A}}$. This model is able to accurately predict the established binding mode of granisetron (Kesters et al., 2013; Ruepp et al., 2017), and was used for docking vortioxetine at the orthosteric binding site. We used pharmacological characterization of mutant receptors to identify and validate a model for vortioxetine in its bioactive conformation bound to the receptor. We find the location and conformation of vortioxetine in the binding site to be different from other known ligands, and this enables interactions with residues from both loop $\mathrm{E}$ and $\mathrm{F}$ simultaneously. Comparison with models for setron and agonist binding reveals distinct features for vortioxetine that might explain its unique inhibitory mechanism.

\section{Materials and Methods}

Materials. Chemicals were obtained from Sigma (St. Louis, MO) unless otherwise stated. Dulbecco's modified Eagle's medium, fetal bovine serum, trypsin, and penicillin-streptomycin were obtained from Invitrogen (Carlsbad, CA). DNA restriction enzymes were obtained from New England Biolabs (Ipswich, MA). Cell culture dishes were obtained from Sarstedt AG \& Co (Nümbrecht, Germany), and 96-well plates were obtained from VWR (Copenhagen, Denmark). Unlabeled and tritium-labeled vortioxetine was provided by $\mathrm{H}$. Lundbeck A/S (Valby, Denmark). [ $\left.{ }^{3} \mathrm{H}\right]-$ GR65630 was obtained from Perkin Elmer (Waltham, MA). DNA sequencing was performed using GATC Biotech (Constance, Germany). The FLIPR Blue membrane potential assay kit was obtained from Molecular Devices (San Jose, CA).

Molecular Biology. cDNA encoding the h5-HT $\mathrm{HA}_{3 \mathrm{~A}}$ receptor was kindly provided by Dr. Beate Niesler (University of Heidelberg). The coding sequence for $\mathrm{h} 5-\mathrm{HT}_{3 \mathrm{~A}}$ was excised from the host vector pcDNA3.1 with EcoRI restriction enzyme and inserted into the combined mammalian and Xenopus laevis oocyte expression vector pXOON (Jespersen et al., 2002) in an EcoRI site in the multiple cloning site regions using T4 DNA ligase (Roche, Basel, Germany). The resulting pXOON-h5-HT $3 \mathrm{~A}$ plasmid construct was confirmed by sequencing. Point mutations were generated by site-directed 
mutagenesis using the QuickChange mutagenesis kit (Stratagene, La Jolla, CA). All mutant constructs were verified by DNA sequencing (Eurofins Genomics, Ebersberg, Germany).

Xenopus laevis Oocyte Expression. Defoliated stage V to VI oocytes from Xenopus laevis were prepared as described previously (Poulsen et al., 2013) and injected with $15 \mathrm{ng}$ mRNA. The care and use of Xenopus laevis was in strict adherence to a protocol (license 2014-150201-00031) approved by the Danish Veterinary and Food Administration, which is in accordance with the Guide for the Care and Use of Laboratory Animals (https://www.ncbi.nlm.nih.gov/books/NBK54050/) adopted by the U.S. National Institutes of Health. Oocytes were incubated at $18^{\circ} \mathrm{C}$ for $24-48$ hours following injection. Recordings were made using a Warner OC725B two-electrode voltage clamp (Warner Instruments, Hamden, CT) configured as recommended by the manufacturer. For concentration-response experiments, oocytes were perfused with oocyte recording buffer $(115 \mathrm{mM} \mathrm{NaCl}, 2 \mathrm{mM} \mathrm{KCl}, 5 \mathrm{mM}$ HEPES, and $1.8 \mathrm{mM} \mathrm{BaCl}_{2}, \mathrm{pH}$ 7.6) and ligands were added by whole bath application using a $\mathrm{PC}-16$ valve-based perfusion controller (Bioscience Tools, Highland, CA). For fast solution switching experiments used to determine receptor desensitization rates, solutions containing saturating concentrations of agonist were applied to the oocyte using a rapid perfusion scheme with a vertical flow chamber and a volume of $400 \mu \mathrm{l}$ and a solution flow rate of $10 \mathrm{ml} / \mathrm{min}$ (Joshi et al., 2004). This approach allowed rapid switching between control and agonist-containing solutions, which is essential to ensure resolution of desensitizing receptor currents. Solution exchange times was determined after each oocyte recording by stepping a dilute external solution across open electrode tips to measure a liquid junction current. The $10 \%-90 \%$ rise times for solution exchange were consistent at $\sim 1$ seconds or less. All experiments were performed at room temperature $\left(23^{\circ} \mathrm{C}\right)$. Data acquisitions were accomplished using a Digidata 1320A analogdigital converter (Molecular Devices, San Jose, CA) interfaced with a PC running WinWCP software (available from Strathclyde Electrophysiology Software, University of Strathclyde, Glasgow, United Kingdom).

Mammalian Cell Culturing and Expression. Human embryonic kidney 293 (HEK-293) cells (American Type Culture Collection, Manassas, VA) were cultured in Dulbecco's modified Eagle's medium supplemented with $10 \% \mathrm{v} / \mathrm{v}$ fetal bovine serum, $100 \mathrm{U} / \mathrm{ml}$ penicillin, and $100 \mu \mathrm{g} / \mathrm{ml}$ streptomycin at $37^{\circ} \mathrm{C}$ in a humidified $5 \% \mathrm{CO}_{2}$ environment. For expression of wild-type (WT) and mutant h5- $\mathrm{HT}_{3 \mathrm{~A}}$ receptor, HEK-293 cells in suspension were transfected using TransIT DNA transfection reagent (Mirus, Madison, VA) according to the manufacturer's instructions, plated into black 96-well clear-bottom plates at a density of 30,000 cells/well, and incubated for 48 hours before use.

Membrane Potential Assay. Concentration response experiments were performed using a FlexStation 1 microplate reader (Molecular Devices, San Jose, CA) essentially as described by Price and Lummis (2005). Briefly, FLIPR blue membrane potential dye was diluted in assay buffer (denoted as Flex50 and containing $57.5 \mathrm{mM}$ $\mathrm{NaCl}, 57.5 \mathrm{mM}$ NMDG+, $1 \mathrm{mM} \mathrm{KCl}, 1 \mathrm{mM} \mathrm{MgCl} 2,1 \mathrm{mM} \mathrm{CaCl}$, $10 \mathrm{mM}$ HEPES, and $10 \mathrm{mM}$ glucose; adjusted to $\mathrm{pH} 7.4$ with $\mathrm{HCl}$ ) according to the manufacturer's instructions. Cells were incubated with $100 \mu \mathrm{l}$ of the FLIPR blue loading solution per well at $37^{\circ} \mathrm{C}$ for 30 minutes. Fluorescence in each well was measured in a FlexStation 1 (Molecular Devices) scanning plate-reading fluorometer with an integrated and automated pipettor at 2-second intervals for $200 \mathrm{sec}$ onds. At 18 seconds, $25 \mu$ l of 5-HT solution (in Flex50 buffer, final concentration $0.01-300 \mu \mathrm{M})$ was added to each well. For inhibitor concentration-response experiments, the inhibitor was included in the dye loading buffer during preincubation. Experiments on the N123L mutant were performed as described previously, but using a modified assay buffer with increased $\mathrm{NaCl}$ concentration (denoted Flex100 and containing $115 \mathrm{mM} \mathrm{NaCl}, 1 \mathrm{mM} \mathrm{KCl}, 1 \mathrm{mM} \mathrm{MgCl} 2,1 \mathrm{mM} \mathrm{CaCl}$, $10 \mathrm{mM}$ HEPES, and $10 \mathrm{mM}$ glucose, $\mathrm{pH}$ 7.4) in place of Flex50 buffer to increase signal amplitude due to lower responses with this mutant receptor. Experiments on WT h5- $\mathrm{HT}_{3 \mathrm{~A}}$ receptors were performed in parallel using the Flex100 buffer, and $\mathrm{IC}_{50}$ values identical to those seen in the Flex50 buffer were obtained. See the Supplemental Material for additional details.

Radioligand Binding Assay. Membranes from HEK-293 cells expressing $\mathrm{h} 5-\mathrm{HT}_{3 \mathrm{~A}}$ receptors were prepared as described previously (Thompson et al., 2011). Briefly, transfected HEK-293 cells from a 10-cm dish were harvested by scraping into $1 \mathrm{ml}$ ice-cold HEPES buffer (10 mM, pH 7.4) and frozen. Cells were then thawed, centrifuged at $20,000 \mathrm{~g}$ for 1 minute and the pellet was resuspended in HEPES buffer. This procedure was repeated twice with a final resuspension in $2 \mathrm{ml}$ HEPES buffer. For competition binding experiments, $50 \mu \mathrm{l}$ suspensions of cell membranes were incubated in $500 \mu \mathrm{l}$ HEPES buffer containing $0.3 \mathrm{nM}\left[{ }^{3} \mathrm{H}\right]$-GR65630 (equal to the $K_{\mathrm{d}}$ value for this radioligand) and varying concentrations of vortioxetine. Nonspecific binding was determined by incubation with $10 \mu \mathrm{M}$ quipazine. For saturation binding experiments, $50 \mu \mathrm{l}$ of cell membranes were incubated in $500 \mu \mathrm{l}$ HEPES buffer containing increasing concentrations of $\left[{ }^{3} \mathrm{H}\right]$-vortioxetine at $4^{\circ} \mathrm{C}$ for 1 hour. For concentrations above $5 \mathrm{nM}$ vortioxetine, $\left[{ }^{3} \mathrm{H}\right]$-vortioxetine was spiked with 2.5 $\mathrm{nM}$ unlabeled vortioxetine. Reactions were terminated by vacuum filtration using a Brandel (Gaithersburg, MD) cell harvester onto GF/B filters presoaked in $0.3 \%$ w/v polyethyleneimine. Radioactivity was determined by scintillation counting using a Beckman BCLS6500 instrument (Beckman, Fullerton, CA).

Pharmacological Data Analysis. All data analyses involving iterative curve fitting were performed using GraphPad Prism software (GraphPad Inc., San Diego, CA). In general, for concentrationresponse data for $\mathrm{EC}_{50}$ or $\mathrm{IC}_{50}$ determinations, responses were defined as the change in fluorescence or current upon agonist stimulation and calculated as peak response $\left(R_{\text {peak }}\right)$ minus baseline fluorescence or current $\left(R_{\text {base }}\right)$ defined as fluorescence or current immediately before agonist stimulation. For pooling of data from different experiments, we normalized responses according to the following equation:

$$
\text { Normalized response }=\frac{\left(R_{\text {peak }}-R_{\text {base }}\right)}{R_{\max }}
$$

where $R_{\max }$ is the fluorescence response recorded for application of a saturating concentration of 5-HT. For determination of $\mathrm{IC}_{50}$ and $\mathrm{EC}_{50}$ values, data were pooled among individual experiments and the composite concentration-inhibition data were analyzed by iterative curve fitting using the following equation:

$$
\text { Response }=\frac{1}{\left(1+10^{(\log Y-X) \times n_{\mathrm{H}}}\right)}
$$

where response is the agonist-evoked response measured at a given inhibitor concentration normalized to the response in either the absence of inhibitor (for $\mathrm{IC}_{50}$ ) or the maximum response (for $\mathrm{EC}_{50}$ ); $Y$ is the concentration of inhibitor (for $\mathrm{IC}_{50}$ ) or agonist (for $\mathrm{EC}_{50}$ ) that produces a half-maximal inhibition or response; $X$ is the logarithm of the concentration of the inhibitor or agonist concentration; and $n_{\mathrm{H}}$ is the Hill slope. For determination of the equilibrium dissociation constant $\left(K_{\mathrm{d}}\right)$ for vortioxetine from saturation radioligand binding experiments, specific binding data were analyzed by curve fitting according to the following equation:

$$
B=\frac{\left(B_{\max } \times[L]\right)}{K_{\mathrm{d}}+[L]}
$$

where $B$ is the bound radioligand; $B_{\max }$ is the maximum binding at equilibrium; $K_{\mathrm{d}}$ is the equilibrium dissociation constant; and $[L]$ is the free concentration of radioligand. For calculation of the inhibition constant $\left(K_{\mathrm{i}}\right)$ for vortioxetine from competition radioligand binding experiments, the Cheng-Prusoff equation (Cheng and Prusoff, 1973) was used based on the assumption that vortioxetine and the radioligand bind competitively under steady-state conditions. Unless otherwise indicated, the $\mathrm{IC}_{50}$ and $\mathrm{EC}_{50}$ values are shown with $95 \%$ confidence interval, and statistical differences were analyzed using 
analysis of variance followed by a Dunnett's multiple comparisons test using the GraphPad Prism software.

Protein Modeling. The $\mathrm{h} 5-\mathrm{HT}_{3 \mathrm{~A}}$ receptor was modeled in an inactive conformation based on several templates since no single template of a cation-selective receptor in an unambiguously inactive conformation existed at the time of modeling. Therefore, the receptor was partly modeled based on the highly homologous $\mathrm{m} 5-\mathrm{HT}_{3 \mathrm{~A}}$ (Hassaine et al., 2014). In this structure, the pore-lining helix, M2, is in an unclear conformational state since the conformation of the backbone is similar to other open-channel receptor structures, while the conformations of the pore-lining side chains effectively close the pore (Hassaine et al., 2014). This was overcome by modeling in combination with a human $\mathrm{GABA}_{\mathrm{A}}$ receptor in an inactive conformation (Miller and Aricescu, 2014), and an antagonist-bound 5-HTBP (Kesters et al., 2013) using MODELER 9.14 (Sali and Blundell, 1993) (Supplemental Material; Supplemental Fig. 1).

Ligand Preparation. The structure of granisetron was extracted from the crystal structure of 5-HTBP (Protein Data Bank ID: 2YME), while the structure of vortioxetine was prepared as described in Andersen et al. (2015). Following assignment of bond orders and atom types in Maestro 10.1 (Schrödinger Suite 2015) (Schrodinger LLC, New York, NY), the granisetron structure was minimized and then subjected to a conformational search using the mixed torsional/lowmode sampling method, the optimized potentials for liquid simulations 2.1 force field, and an implicit water model in MacroModel 10.7 (Schrodinger Suite 2015). Then, 5000-step minimization using a conjugate gradient method followed each iteration step in the conformational search. Both ligands were modeled as having one charged amine based on available $\mathrm{p} K_{\mathrm{a}}$ data.

Induced Fit Docking. Ligands were docked in their lowest energy conformation into each of the five substrate binding sites of h5- $\mathrm{HT}_{3 \mathrm{~A}}$ using an induced fit docking (IFD) protocol. The protocol employed the Glide 6.4 and Prime 3.7 modules in the Schrödinger software suite (Schrödinger Suite 2015), which allows for full flexibility of both the ligand and binding site side chains (Friesner et al., 2004; Sherman et al., 2006). The binding site center was defined as the centroid of Trp 178 and Ser226 in the principal subunit and Asp64 in the complementary subunit of each site. In the initial docking, Arg87 was mutated to alanine to allow room for the ligand, and a maximum of 200 poses was carried forward to the next step. A maximum of 100 ligand docking poses was reported in extra precision in the last docking step with energies less than $30 \mathrm{kcal} / \mathrm{mol}$ higher than the initial docking conformation. The resulting docking poses from each site were then combined and collectively clustered based on their in-place conformation using the Conformer Cluster script available in Maestro 10.1.

Molecular Dynamics Simulations. Simulation systems were set up and equilibrated using a coarse-grained approach before being converted into their all-atom equivalent for production run simulations. The receptor was placed in a solvated 1-palmitoyl-2-oleoyl-snglycero-3-phosphocholine bilayer and ionized to a $0.2 \mathrm{M} \mathrm{NaCl}$ concentration. Coarse-grained simulations were performed using the MARTINI force field (Bulacu et al., 2013; de Jong et al., 2013) and allatom simulations using the CHARMM36 force field (Klauda et al., 2010; Best et al., 2012). The apo receptor was simulated in the a constant number of particles, temperature, and pressure ensemble in atomistic resolution for 10 nanoseconds, with positional restraints on $\mathrm{C}_{\alpha}$ atoms before docking calculations. Following the docking, a representative pose from each cluster was simulated for 53.5 nanoseconds (1.5 nanoseconds of restrained equilibration, 2 nanoseconds of unrestrained preproduction equilibration, and a 50-nanosecond production run) (Supplemental Material). The analyses were performed directly after the release of the restraints to assess the stability of the binding cluster as it was found in the IFD calculations. The root-meansquare displacement of vortioxetine heavy atoms relative to their position in the first frame was monitored in each simulation as well as whether vortioxetine maintained its stabilizing interactions with the protein. See the Supplemental Material for simulation details and the parameterization of vortioxetine.
Molecular Mechanics-Poisson-Boltzmann and Surface Area Calculations. The free energy of binding was estimated using the molecular mechanics-Poisson-Boltzmann and surface area (MM-PBSA) method (Wang et al., 2001; Genheden and Ryde, 2015) as implemented in GMXPBSA 2.1 (Paissoni et al., 2015). Briefly, ligand/protein complexes were subjected to molecular dynamics (MD) simulations, and 100 frames were evenly extracted from the first 2 nanoseconds. The first 2 nanoseconds were chosen since the free energy estimate was intended as a postdocking scoring method, and not as an evaluation tool of the binding modes that vortioxetine converged into during the production runs. The first frame was extracted directly after the ligand restraints applied in the restrained equilibration phase were released, and the binding free energy is thus expected to reflect the binding mode found in the docking and not an MD-relaxed version of this binding mode. The trajectory was stripped of water, ions, and lipids, and only the ligand and the two subunits within the ECD domain that surround the ligand along with the ligand itself were included in the calculations. APBS software (Baker et al., 2001) was used to solve the PoissonBoltzmann equation and to calculate the nonpolar contribution to the solvation energy (on the basis of the solvent accessible surface area). Gromacs 5.0.2 and the CHARMM36 force field (Klauda et al., 2010; Best et al., 2012) were used to calculate the van der Waals and Coulomb energy contributions of the free ligand and protein and the protein/ligand complex (Paissoni et al., 2015). The Poisson-Boltzmann equation was solved using a nonlinear approximation with the boundary condition defined as $s d h$ and a grid spacing of 1 , with the temperature set to $310 \mathrm{~K}$, ion concentrations set to $0.2 \mathrm{M}$, and a protein dielectric constant of 2 . Finally, the calculations were performed using the multitrj option in GMXPBSA (Paissoni et al., 2015) to ensure the same grid definitions in all calculations.

\section{Results}

Homology Modeling of the h5-HT $\mathbf{H A}_{3 \mathrm{~A}}$ Receptor Structure. To enable computational studies of vortioxetine binding to the $\mathrm{h} 5-\mathrm{HT}_{3 \mathrm{~A}}$ receptor, we generated a three-dimensional molecular model of $\mathrm{h} 5-\mathrm{HT}_{3 \mathrm{~A}}$ using the existing X-ray crystal structures of pLGICs and 5-HTBP constructs as templates (see Materials and Methods and the Supplemental Material) (Fig. 1). Vortioxetine acts as a functional antagonist at h5$\mathrm{HT}_{3 \mathrm{~A}}$ by stabilizing the receptor in a closed-channel state (Bang-Andersen et al., 2011). We, therefore, chose to model the $\mathrm{h} 5-\mathrm{HT}_{3 \mathrm{~A}}$ receptor in an inactive conformation, here defined as: 1) the channel adopting a conformation with gating residues obstructing ion passage as observed in closed-pore pLGIC structures (daCosta and Baenziger, 2013; Sauguet et al., 2015) and 2) the orthosteric binding site adopting a conformation similar to structures of antagonist-bound pLGICs and 5-HTBP constructs (Sander et al., 2010; Kesters et al., 2013). We used multiple structures as templates to build this model because a single template did not exist that represented an inactive pLGIC conformation while being sufficiently homologous to the $\mathrm{h} 5-\mathrm{HT}_{3 \mathrm{~A}}$ receptor at the time of modeling. At the time of modeling, the closest homolog of h5$\mathrm{HT}_{3 \mathrm{~A}}$ for which a high-resolution structure exists is the m5$\mathrm{HT}_{3 \mathrm{~A}}$ receptor in the apo state (Hassaine et al., 2014). Human and mouse $5-\mathrm{HT}_{3 \mathrm{~A}}$ receptors share $86 \%$ sequence identity, and the $\mathrm{m} 5-\mathrm{HT}_{3 \mathrm{~A}}$ structure is, therefore, in general, an excellent template for modeling of $\mathrm{h} 5-\mathrm{HT}_{3 \mathrm{~A}}$. However, the conformational state of the channel is unclear in the $\mathrm{m} 5-\mathrm{HT}_{3 \mathrm{~A}}$ structure due to the low resolution of the transmembrane domain region (Hassaine et al., 2014). Therefore, to model an inactive conformational state of $\mathrm{h} 5-\mathrm{HT}_{3 \mathrm{~A}}$, we combined the $\mathrm{m} 5-\mathrm{HT}_{3 \mathrm{~A}}$ structure with a structure of the human $\mathrm{GABA}_{\mathrm{A}}$ receptor 
A

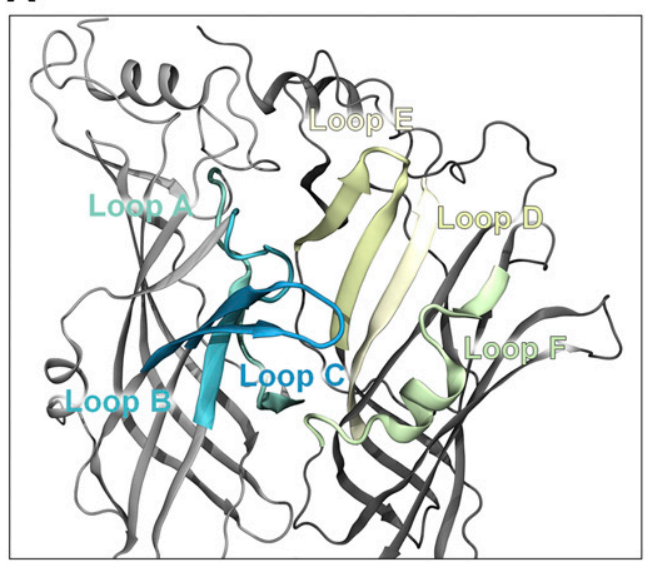

B

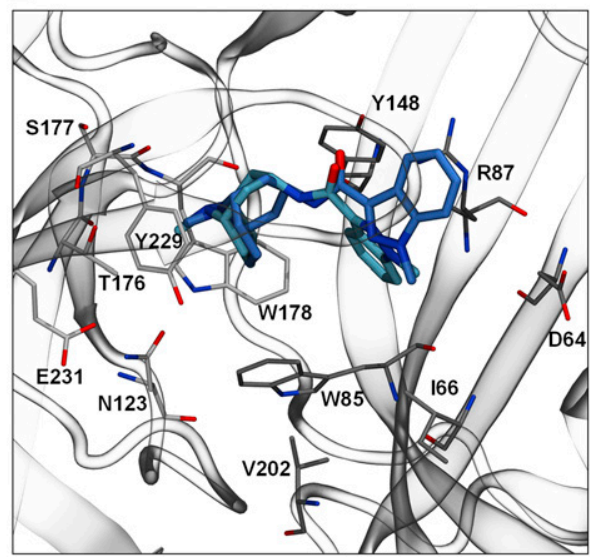

Fig. 2. Granisetron docking in the orthosteric binding site of the model $\mathrm{h} 5-\mathrm{HT}_{3 \mathrm{~A}}$ receptor structure. (A) Ribbon representation of the orthosteric binding site in the $\mathrm{h} 5-\mathrm{HT}_{3 \mathrm{~A}}$ receptor model at the subunit interface, which is formed by loops A-C in the principal subunit and loops $\mathrm{D}-\mathrm{F}$ in the complementary subunit. (B) Structure of granisetron (cyan) docked in the h5$\mathrm{HT}_{3 \mathrm{~A}}$ receptor model overlayed with the experimentally determined structure of granisetron in complex with 5-HTBP (blue) (Protein Data Bank ID: 2YME). Key principal and complimentary subunit residues are colored in white and gray, respectively. Residue numberings refer to the $\mathrm{h} 5-\mathrm{HT}_{3 \mathrm{~A}}$ sequence. (see Materials and Methods and the Supplemental Material), which unambiguously is in a closed-pore conformation (Miller and Aricescu, 2014). The intracellular domain formed by the 114-residue loops between the M3 and M4 membranespanning domains from each subunit is not resolved in the m5$\mathrm{HT}_{3 \mathrm{~A}}$ structure. Therefore, we did not model the intracellular domain and instead replaced the M3/M4 loop in each h5- $\mathrm{HT}_{3 \mathrm{~A}}$ subunit with a three amino acid artificial linker sequence (Supplemental Material). Finally, the conformation of the ECD loop regions that form the orthosteric binding sites were modeled using the reported X-ray crystal structure of granisetron-bound 5-HTBP (Kesters et al., 2013). The resulting h5-HT ${ }_{3 \mathrm{~A}}$ model is shown in Fig. 1, A and B. The orthosteric binding sites are located at the interfaces between subunits and formed by residues located in loops $\mathrm{A}-\mathrm{C}$ on one subunit (denoted as the principal subunit) and loops $\mathrm{D}-\mathrm{F}$ on the neighboring subunit (denoted as the complementary subunit) (Fig. 2A). In our model, loop $\mathrm{C}$ adopts an open conformation similar to the conformation observed for antagonist-bound ECD structures such as 5-HTBP in complex with setrons (Kesters et al., 2013; Price et al., 2016) as well as other antagonist-bound AChBP structures (Sander et al., 2010). Outside the binding site regions the Cys-loop is in direct contact with the M2/M3 loop through hydrophobic interactions, which is a configuration predicted to be important for allosteric communication of conformational changes between the ECD and transmembrane domain (Jha et al., 2007). The narrowest diameter of the channel pore is $2.7 \AA$, which is in between the pore diameters of the template $\mathrm{GABA}_{\mathrm{A}}$ and $\mathrm{m} 5$ $\mathrm{HT}_{3 \mathrm{~A}}$ receptor structures and is too narrow to allow ion passage (Yang, 1990; Mähler and Persson, 2012). The porelining residues all point into the channel pore, and the selectivity filter (Glu272) and hydrophobic gate (Leu282) (Barnes et al., 2009) are closed.

Computational Analysis of Ligand Binding to h5$\mathbf{H T}_{\mathbf{3 A}}$. We initially evaluated the $\mathrm{h} 5-\mathrm{HT}_{3 \mathrm{~A}}$ receptor model by docking granisetron into the orthosteric site using an IFD protocol (see Materials and Methods) and compared the resulting ligand-docking models with the existing structure of 5-HTBP in complex with granisetron. The resulting largest binding cluster of granisetron in the h5-HT $\mathrm{H}_{3 \mathrm{~A}}$ model overlapped well with the binding mode observed in the 5-HTBP/granisetron structure (Protein Data Bank ID: $2 \mathrm{YME}$, Fig. 2B), thus suggesting that our h5-HT $\mathrm{HA}_{3 \mathrm{~A}}$ model and docking approach is suitable for exploration of potential bioactive binding modes in the orthosteric site. Since the conformation of the orthosteric binding site in our h5- $\mathrm{HT}_{3 \mathrm{~A}}$ model is based on an antagonist-bound template, the binding site should be able to reproduce the granisetron binding mode found in a crystal structure of 5-HTBP (Kesters et al., 2013). We then docked vortioxetine into this validated model. We performed docking calculations in all five binding sites to improve the sampling of binding modes since each binding site is slightly different as no symmetry constraints were imposed during the modeling process. In total, 263 poses of vortioxetine were obtained from the five IFD calculations and clustered collectively according to their in-place conformation (see Materials and Methods). Among these, we dismissed all clusters with average extra precision Gscores higher than $-10 \mathrm{kcal} / \mathrm{mol}$ and/or clusters containing less than six poses. The extra precision Gscore is an empirical scoring function that seeks to estimate the ligand/protein binding affinity (Friesner et al., 2006). Six clusters remained and were considered as representing the potential bioactive binding mode (C2, C6, C8, C11, C13, and C30) (Table 1). A representative orientation of vortioxetine in each of these six clusters is shown in Fig. 3. Among these, the orientation and binding site interactions of vortioxetine differ in several aspects. First, different interaction partners are observed for the charged nitrogen in the piperazine ring. In cluster $\mathrm{C} 2$, the charged nitrogen forms hydrogen bonds to the backbone carbonyls of Ser177 and Trp178 on loop B in addition to a cation $/ \pi$ interaction with Trp178. In cluster C6, the nitrogen is observed to form a salt bridge with Glu231 (loop C), whereas in clusters $\mathrm{C} 8, \mathrm{C} 11$, and $\mathrm{C} 13$, the nitrogen displays cation/ $\pi$ interactions with Trp178 (loop B) and Tyr229 (loop C) and hydrogen bonding to Thr176 (loop B). Finally, cluster C30 shows that the nitrogen atom in the piperazine ring is placed in the complementary subunit of the binding site where it forms a salt bridge to Asp64. Second, in all clusters one of the two aromatic rings in vortioxetine is located in the same subpocket at the back of the binding site in which one of the aromatic rings of vortioxetine is sandwiched between Tyr148 (loop E) and Trp85 (loop D) with further supporting interactions provided by Trp178 (loop B). In clusters C2, C6, and C8, the dimethylphenyl ring (phenyl A, Fig. 1C) is located in this subpocket, whereas in clusters $\mathrm{C} 11, \mathrm{C} 13$, and $\mathrm{C} 30$, it is the central phenyl (phenyl B, Fig. 1C); $\pi / \pi$ stacking of either 
TABLE 1

Results from the IFD calculations of vortioxetine into the orthosteric binding site of $\mathrm{h} 5-\mathrm{HT}_{3 \mathrm{~A}}$

\begin{tabular}{|c|c|c|c|c|}
\hline Cluster & $n^{a}$ & Average Emodel $^{b}$ & Average Gscore ${ }^{b}$ & $\begin{array}{l}\text { Average IFD } \\
\text { score }^{b}\end{array}$ \\
\hline $\mathrm{C} 2$ & 24 & $-62.6 \pm 7.1$ & $-10.3 \pm 0.9$ & $-3139.0 \pm 1.4$ \\
\hline $\mathrm{C} 6$ & 23 & $-66.9 \pm 10.1$ & $-11.5 \pm 1.1$ & $3141.3 \pm 1.6$ \\
\hline $\mathrm{C} 8$ & 62 & $-68.4 \pm 6.6$ & $-10.3 \pm 1.0$ & $-3139.0 \pm 1.4$ \\
\hline C11 & 40 & $-64.1 \pm 6.7$ & $-10.4 \pm 1.3$ & $-3139.4 \pm 1.8$ \\
\hline C13 & 8 & $-64.1 \pm 6.7$ & $-10.4 \pm 1.3$ & $-3139.4 \pm 1.8$ \\
\hline C30 & 39 & $-70.3 \pm 8.7$ & $-10.7 \pm 1.8$ & $-3140.0 \pm 2.0$ \\
\hline Outliers & 67 & & & \\
\hline
\end{tabular}

\footnotetext{
${ }^{a}$ Number of poses within a cluster.

${ }^{b}$ Average Emodel, XP Gscore, and IFD scores are reported in kilocalories per mole. Data represent mean \pm S.D.
}

phenyl of vortioxetine to at least one of the three aromatic residues within this subpocket is observed in almost all docking poses. The location of the second phenyl ring of vortioxetine is less well-defined and can be found in one of three potential locations within the binding site. In clusters $\mathrm{C} 2, \mathrm{C} 6, \mathrm{C} 13$, and $\mathrm{C} 30$ the second phenyl ring is found close to loops A, B, and C and can interact with Tyr229 (loop C) and Thr176 (loop B). However, in C11 the second phenyl, in this case phenyl A, is located close to Ile66 and Val202 (loop F) of the complementary face, while in $\mathrm{C} 8$, phenyl B is located at the top of the binding site close to Y148 from loop E and Leu179 from loop B. It thus becomes clear that while vortioxetine forms interactions with the same aromatic residues either by cation $/ \pi, \pi / \pi$, or hydrophobic interactions, the binding clusters found in the docking calculations have distinct variations.
We further evaluated the binding clusters by performing MD simulations of each binding mode to determine the general stability of each binding mode and to estimate relative free energies of binding using the MM-PBSA approach (see Materials and Methods). MM-PBSA is an efficient method for fast calculation of free energies of diverse molecular systems (Homeyer and Gohlke, 2012). For clusters C8 and $\mathrm{C} 13$, analysis of the root-mean-square displacement progression in the MD trajectories showed the ligand remaining close to its initial conformation and position for the entire simulation period (Fig. 4, C and E), suggesting these conformations represent possible stable binding modes. In contrast, the ligand changed the conformation and position early during the simulations in cluster $\mathrm{C} 2, \mathrm{C} 6, \mathrm{C} 11$, and C30 (Fig. 4, A, B, D, and $\mathrm{F}$ ), at approximately 2 nanoseconds for $\mathrm{C} 6,10$ nanoseconds for C2 and C11, and immediately for C30. Interestingly, for $\mathrm{C} 6$ and $\mathrm{C} 11$, the ligand converged on a conformation similar to that observed in the stable $\mathrm{C} 8$ and $\mathrm{C} 13$, respectively. C2 converged toward a unique conformation by shifting deeper into the binding site, allowing the charged amine in the piperazine ring of vortioxetine to interact with Thr176 (loop B) (Fig. 4A). Furthermore, phenyl A rotated approximately $180^{\circ}$. The ligand in C30 did not change conformation during the MD simulation, but its position was shifted a few ångström closer to the complementary subunit, improving electrostatic interactions with both Asp199 and Glu224 (loops $\mathrm{F}$ and $\mathrm{C}$, respectively). We then used the MD trajectories to perform MM-PBSA calculations to estimate the free energy of binding for each cluster (see Materials and Methods). The calculations were performed using the first 2 nanoseconds
A

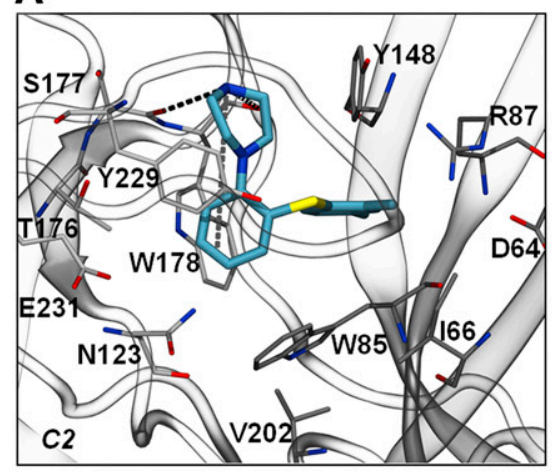

D

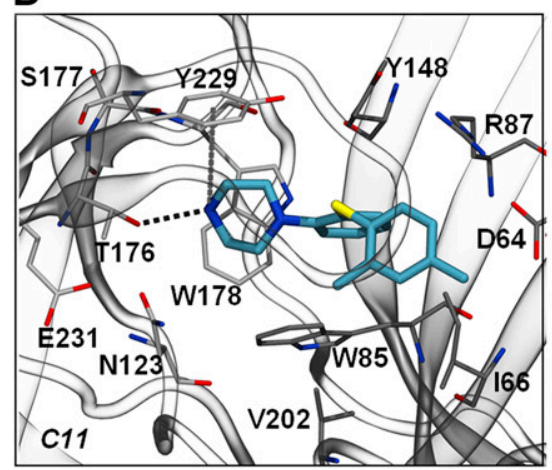

B

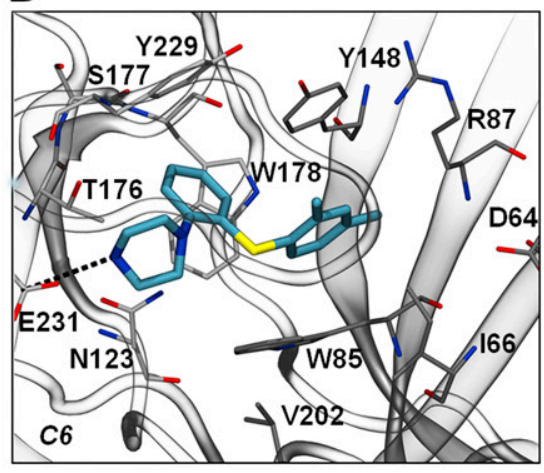

E

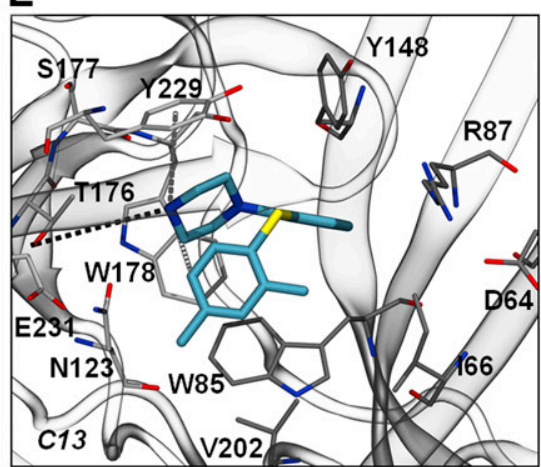

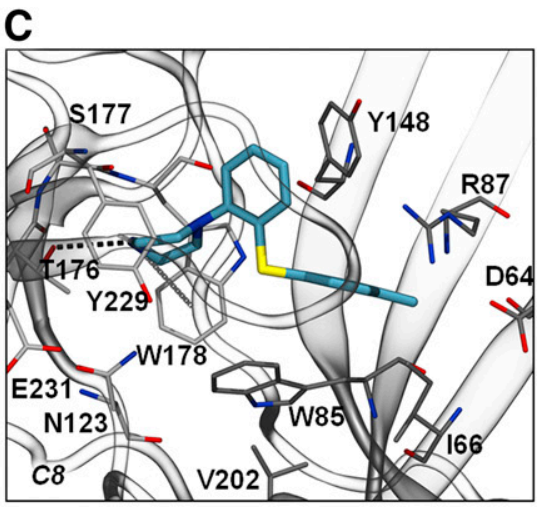

$\mathbf{F}$

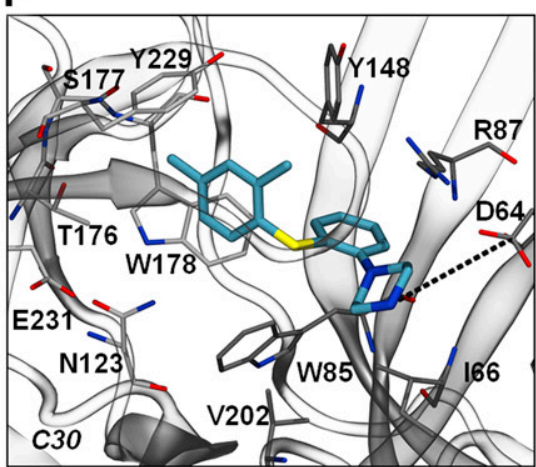

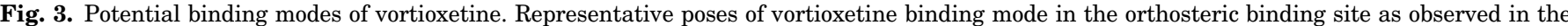

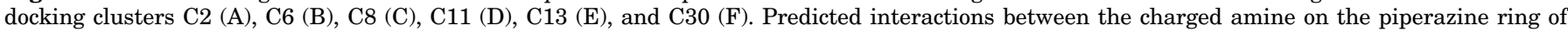

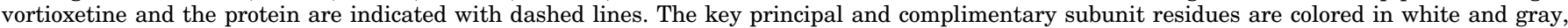
respectively. Residue numbering refers to the h5- $\mathrm{HT}_{3 \mathrm{~A}}$ sequence. 

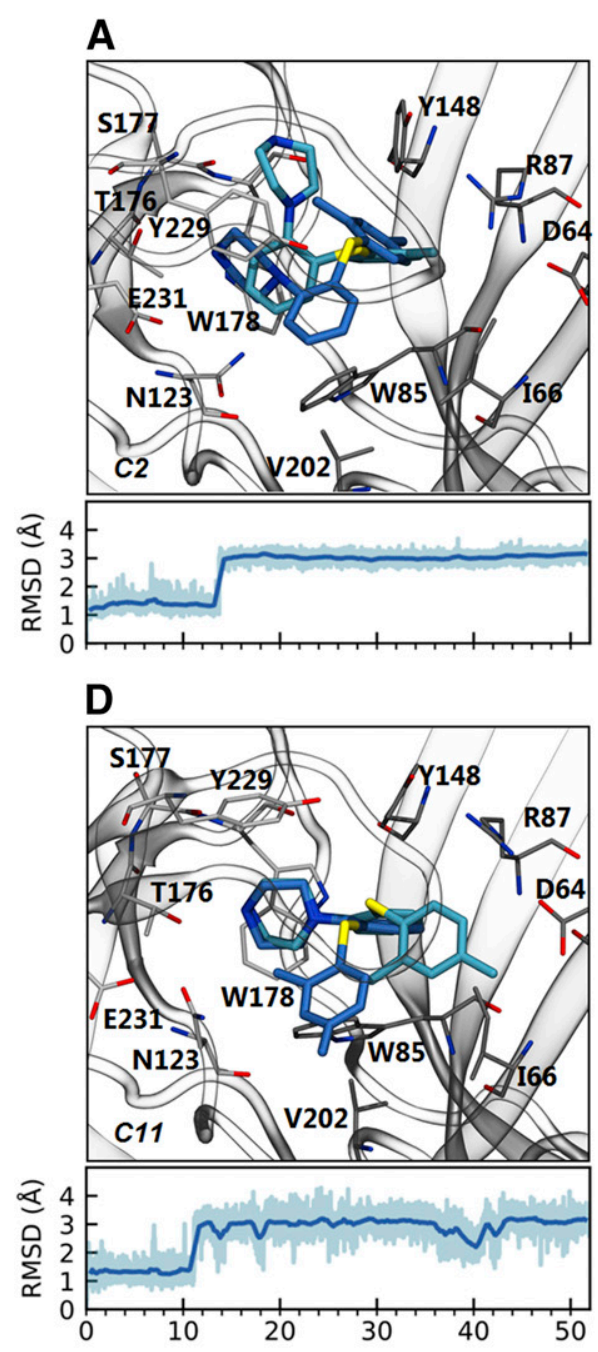

B

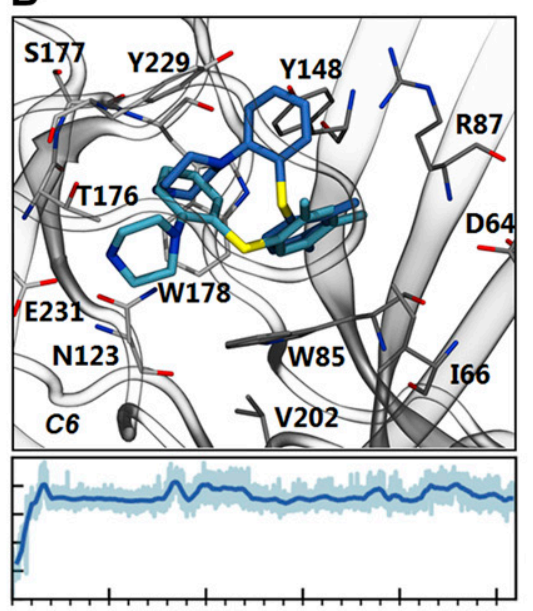

E

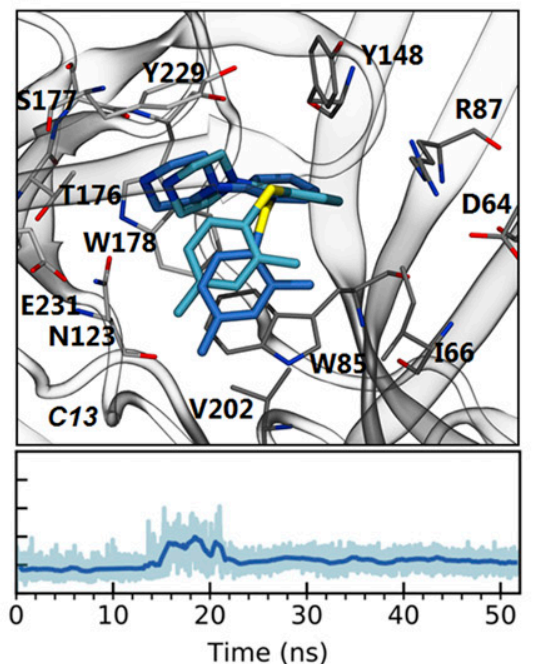

C
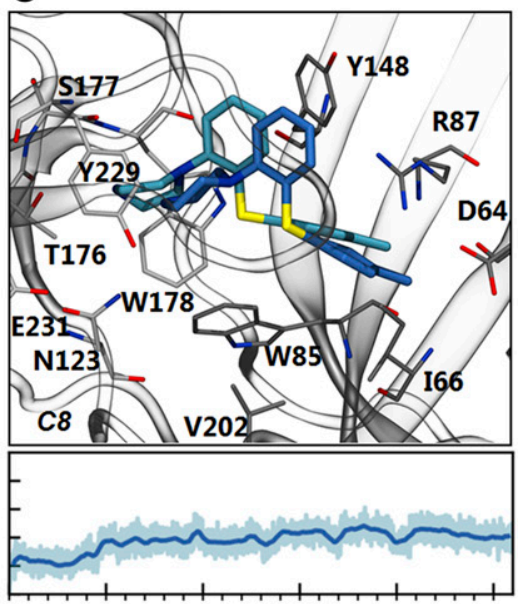

$\mathbf{F}$
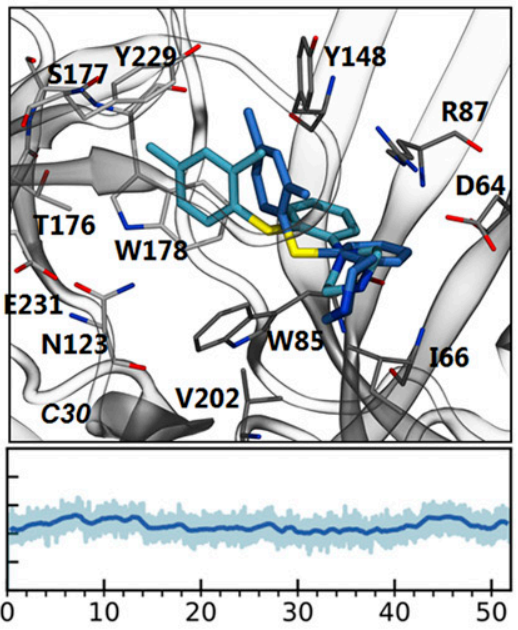

Fig. 4. Ligand stability in the orthosteric binding site during MD simulations. Overlay of vortioxetine structure before (cyan) and after (blue) 52 nanoseconds of MD simulation of vortioxetine in cluster C2 (A), C6 (B), C8 (C), C11 (D), C13 (E), and C30 (F). The structural presentation is equivalent

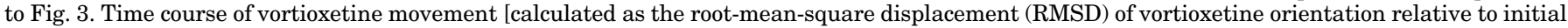
conformation] are shown below the panels. Smoothed data are shown in dark blue, while raw data are shown in light blue.

of the MD simulations to sample only the initial binding conformations. The resulting binding energies showed clusters $\mathrm{C} 8, \mathrm{C} 11$, and $\mathrm{C} 13$ to represent the strongest binding modes (Table 2). Considered together, the results of the MD simulations and the MM-PBSA calculations suggest that $\mathrm{C} 8$ and $\mathrm{C} 13$ represent the strongest and most stable binding mode of vortioxetine in $\mathrm{h} 5-\mathrm{HT}_{3 \mathrm{~A}}$.

Characterization of Vortioxetine Activity at h5-HT Receptors. Vortioxetine properties were characterized in vitro at recombinant $\mathrm{h} 5-\mathrm{HT}_{3 \mathrm{~A}}$ receptors with the aim of establishing a methodology to determine the effects of mutation of key binding site residues on vortioxetine affinity that would allow us to challenge the binding models. Previous work with recombinant $\mathrm{h} 5-\mathrm{HT}_{3 \mathrm{~A}}$ receptors has shown vortioxetine to induce a rapidly desensitizing inward current with a peak response around $65 \%$ of that of 5-HT (Bang-Andersen et al., 2011). Using two-electrode voltage-clamp electrophysiology to measure recombinant $\mathrm{h} 5-\mathrm{HT}_{3 \mathrm{~A}}$ currents in Xenopus oocytes (see Materials and Methods), we observed similar results with saturating concentrations of vortioxetine inducing inward currents with peak response of $54 \%$ relative to 5 -HT and a 7 -fold faster rate of desensitization $\left(\tau_{\text {des }}\right)$ for vortioxetine $\left(\tau_{\mathrm{des}}=7 \pm 4\right.$ seconds; $\left.n=4\right)$ compared with 5 -HT $\left(\tau_{\mathrm{des}}=\right.$ $124 \pm 25$ seconds for 5 -HT; $n=4$ ) (Fig. 5, B and C). Following

TABLE 2

MM-PBSA estimated binding free energies of vortioxetine for each binding cluster

\begin{tabular}{lcccc}
\hline Cluster & $\Delta \mathrm{G}_{\text {bind }}{ }^{a}$ & $\Delta \mathrm{G}_{\text {bind }}$ S.D. & $\Delta \Delta \mathrm{G}_{\text {bind }}{ }^{b}$ & $\Delta \Delta \mathrm{G}_{\text {bind }}$ S.D. \\
\hline C2 & -168.8 & 0.8 & -0.4 & 1.1 \\
C6 & -168.4 & 0.8 & 0 & \\
C8 & -177.8 & 1.1 & -9.4 & 1.4 \\
C11 & -179.3 & 0.6 & -10.9 & 1.0 \\
C13 & -184.5 & 0.8 & -16.2 & 1.1 \\
C30 & -173.7 & 1.1 & -5.4 & 1.3
\end{tabular}

${ }^{a}$ Binding free energies were calculated based on 100 frames evenly extracted from the first 2 nanoseconds of simulation as described in Materials and Methods, and are reported in kilocalories per mole with S.D.

${ }^{b}$ Relative binding free energies are reported relative to $\mathrm{C} 6$, which has the highest calculated binding free energy, reported in kilocalories per mole with S.D. 
A
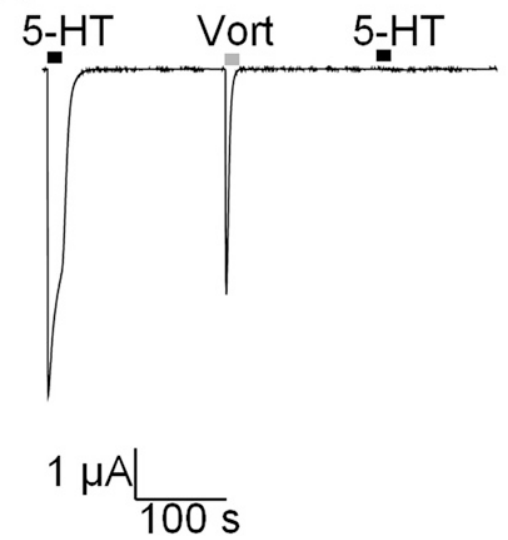

B

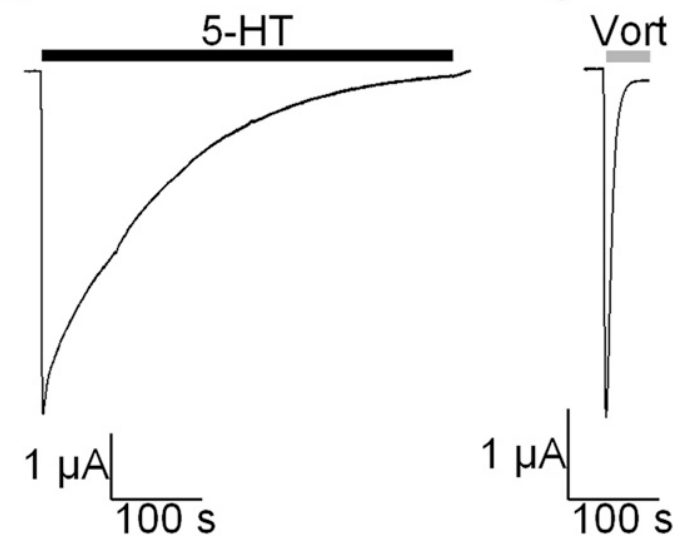

Fig. 5. Electrophysiological characterization of vortioxetine activity. (A) Current traces from a representative Xenopus oocyte expressing h5-HT $3 \mathrm{~A}$ in response to brief 20-second applications of $10 \mu \mathrm{M}$ 5-HT (black bar) and $10 \mu \mathrm{M}$ vortioxetine (gray bar). Vortioxetine causes rapidly desensitizing inward currents followed by persistent inhibition. (B and C) Representative $\mathrm{h} 5-\mathrm{HT}_{3 \mathrm{~A}}$ receptor current responses to extended application of $1 \mathrm{mM}$ 5 -HT (black bar; 500 seconds) and $10 \mu \mathrm{M}$ vortioxetine (gray bar; 50 seconds). The mean \pm S.E.M. for the rate of desensitization $\left(\tau_{\mathrm{des}}\right)$ was for vortioxetine $\tau_{\mathrm{des}}=7 \pm$ 4 seconds (S.E.M.; $n=4$ ) and for 5 -HT $\tau_{\text {des }}=$ $124 \pm 25$ seconds (S.E.M.; $n=4$ ). washout of vortioxetine, a persistent inhibition of agonistevoked currents was observed since the subsequent application of 5-HT was unable to induce responses, consistent with what has been previously reported (Fig. 5A) (Bang-Andersen et al., 2011; Dale et al., 2018). Thus, in the two-electrode voltage-clamp assay, the persistent vortioxetine inhibition of h5- $\mathrm{HT}_{3 \mathrm{~A}}$ prevents multiple applications of different vortioxetine concentrations to the same oocyte that are practically required for concentration-response experiments for determination of ligand potency. Thus, for a higher throughput method of determining potency of 5-HT and inhibitory potency $\left(\mathrm{IC}_{50}\right)$ of vortioxetine, we transiently expressed WT and mutant $\mathrm{h} 5-\mathrm{HT}_{3 \mathrm{~A}}$ receptors in HEK-293 cells and used a microplate-based functional assay that has been used extensively for $5-\mathrm{HT}_{3}$ receptor pharmacological characterization (see Materials and Methods and the Supplemental Material) (Price and Lummis, 2005; Sullivan et al., 2006; Thompson et al., 2006a; Price et al., 2008; Lummis et al., 2011; Del Cadia et al., 2013). The assay is based on measurement of agonistevoked changes in cell membrane potential by use of a fluorescent dye that is sensitive to the membrane field potential (Fitch et al., 2003). We evaluated the applicability of the assay by determining the concentration-response relationship for 5-HT (Fig. 5A) and concentration-inhibition relationships for two prototypical antagonists (granisetron and ondansetron) at WT h5-HT $3 \mathrm{~A}$ (Supplemental Fig. 2). The membrane potential assay yielded an $\mathrm{EC}_{50}$ value for 5 -HT of $191 \mathrm{nM}(170-215 \mathrm{nM} ; n=15)$, which is in close range of the $\mathrm{EC}_{50}$ value of $445 \mathrm{nM}(255-685 \mathrm{nM} ; n=8)$ determined from two-electrode voltage-clamp recordings (Fig. 6, B and C). We obtained $\mathrm{IC}_{50}$ values of $3.3 \mathrm{nM}(2.7-4.1 \mathrm{nM} n=6)$ for granisetron and $0.87 \mathrm{nM}(0.69-1.10 \mathrm{nM} ; n=4)$ for ondansetron. These values are consistent with previously reported $\mathrm{IC}_{50}$ values for these compounds at $\mathrm{h} 5-\mathrm{HT}_{3 \mathrm{~A}}$ receptors (Miyake et al., 1995; Hope et al., 1996; Brady et al., 2001), thus corroborating previous assessments of the usefulness of the membrane potential assay for pharmacological characterization of recombinant $5-\mathrm{HT}_{3}$ receptors (Price and Lummis, 2005; Lummis and Thompson, 2013). We next used the membrane potential assay to determine the concentrationinhibition relationship of vortioxetine at $5-\mathrm{HT}_{3 \mathrm{~A}}$ (Fig. 6). When the cells were preincubated in increasing concentrations of vortioxetine, an $\mathrm{IC}_{50}$ value of $19 \mathrm{nM}(17-21 \mathrm{nM} ; n=$ 20) was found (Fig. 6, E and F), which is similar to the $\mathrm{IC}_{50}$ value of $12 \mathrm{nM}$ for inhibition of $\mathrm{h} 5-\mathrm{HT}_{3 \mathrm{~A}}$ activity in Xenopus oocytes as determined by Bang-Andersen et al. (2011) and in HEK-293 cells as determined by Dale et al. (2018). We also determined vortioxetine $K_{\mathrm{i}}$ from radioligand displacement experiments using the orthosteric $5-\mathrm{HT}_{3}$ ligand $\left[{ }^{3} \mathrm{H}\right]$ GR65630, and obtained a $K_{\mathrm{i}}$ value of $22 \mathrm{nM}(14-34 \mathrm{nM} ; n=4)$ (Fig. 6G) and conducted saturation binding experiments using $\left[{ }^{3} \mathrm{H}\right]$-vortioxetine to determine a $K_{\mathrm{d}}$ value of $19 \pm 6 \mathrm{nM}$ (S.E.M.; $n=3$ ) (Fig. $6 \mathrm{H}$ ). These values correspond well with the $\mathrm{IC}_{50}$ value of vortioxetine determined in the membrane potential assay, which suggests that this assay can report affinity of vortioxetine for $\mathrm{h} 5-\mathrm{HT}_{3 \mathrm{~A}}$ receptors. Furthermore, the highly persistent binding of vortioxetine to recombinant h5-HT receptors observed in Xenopus oocytes suggests a very slow dissociation rate, i.e., after extensive washout of vortioxetine from preincubated oocytes all further application of 5-HT does not induce any current response to 5 -HT. In the membrane potential assay, which employs preincubation with vortioxetine before $\mathrm{h} 5-\mathrm{HT}_{3 \mathrm{~A}}$ responses are evoked with 5 - $\mathrm{HT}$, such slow unbinding should make the $\mathrm{IC}_{50}$ value of vortioxetine independent of 5-HT concentration. Indeed, varying concentrations of 5 -HT ranging from 1 to $300 \mu \mathrm{M}$ generated identical $\mathrm{IC}_{50}$ curves (Fig. 6F). Thus, the membrane potential assay overall appears suitable for characterization of vortioxetine pharmacological properties at the h5- $\mathrm{HT}_{3 \mathrm{~A}}$.

Mutational Analysis of Binding Site Residues that Are Predicted Critical for Vortioxetine Potency. To determine the potential contribution of binding site residues to vortioxetine affinity, we performed site-directed mutagenesis in the $\mathrm{h} 5-\mathrm{HT}_{3 \mathrm{~A}}$ receptor and assessed the effect of singlepoint mutations on vortioxetine $\mathrm{IC}_{50}$ using the membrane potential assay. We selected eight amino acid positions around the orthosteric binding pocket for mutational analysis (Fig. 7A). The rationale for how mutation of these residues might allow us to discriminate between potential binding modes is outlined in Table 3. In general, we substituted each position with one or more residues with different physicochemical properties from the WT residue such that the mutations could change potential interactions with vortioxetine. In total, we created 14 mutants (Table 4) that were individually expressed in HEK-293 cells and assessed them for potential effects of mutation on overall receptor activity and 5-HT $\mathrm{EC}_{50}$ using the membrane potential assay (see Materials and Methods). Four mutants (D64V, N123I, S177E, and E231I) did not show specific responses to $5-\mathrm{HT}$ stimulation at concentrations up to $1 \mathrm{mM}$ (Table 4). Thus, 
A

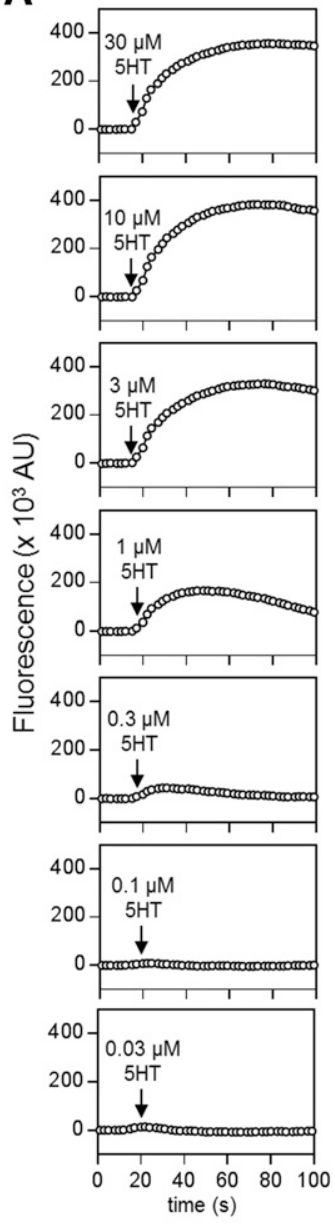

B

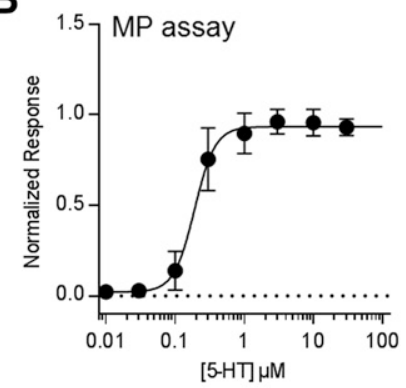

C
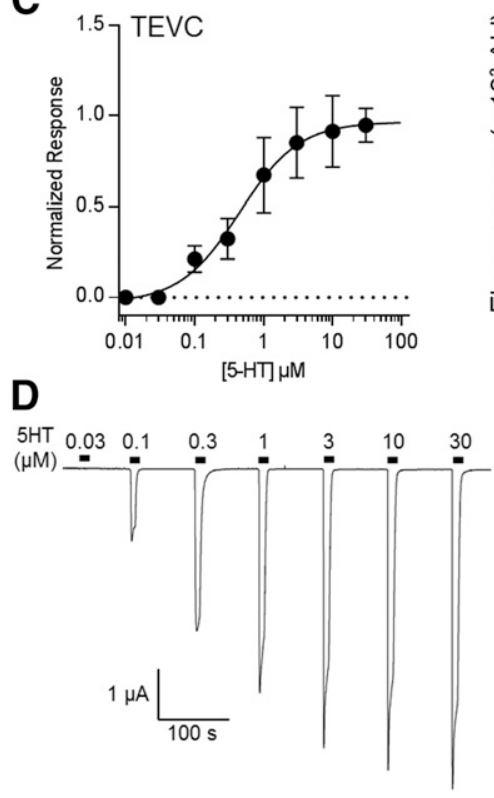

E

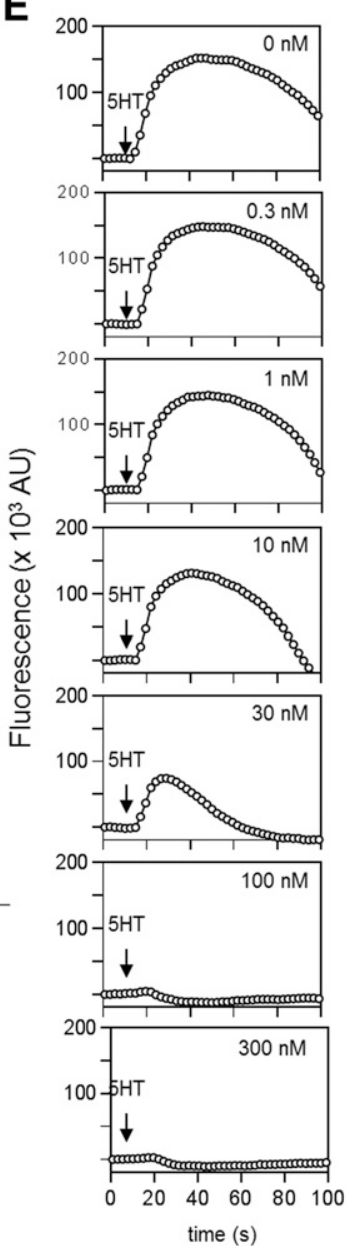

F

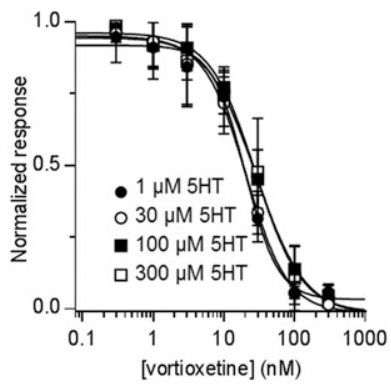

G

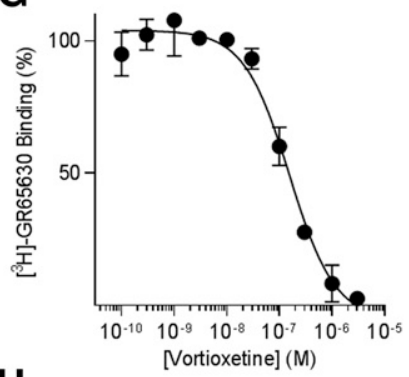

H

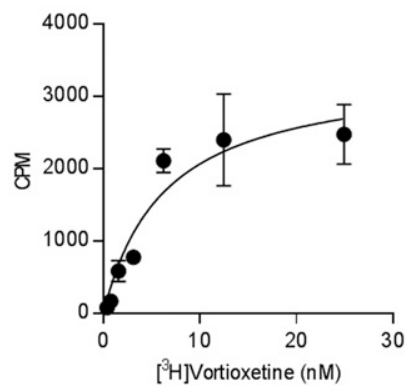

Fig. 6. Pharmacological characterization of vortioxetine in Xenopus oocytes and HEK-293 cells. (A) Representative trace of fluorescence responses in HEK-293 cells expressing h5-HT 3 cells to the indicated concentration of 5-HT in micromolars using the membrane potential assay (see Materials and Methods). (B) Representative current responses to the indicated concentration of 5-HT (in micromolars) in Xenopus oocytes expressing h5-HT3 ${ }_{\mathrm{A}}$ receptors at $-20 \mathrm{mV}$. Concentration-response curves for 5-HT at Xenopus oocytes (C) and HEK-293 cells (D) expressing h5-HT $3 \mathrm{~A}$. Data points represent the normalized mean \pm S.D. response from 5 to 10 individual experiments or oocytes for each concentration. (E) Representative trace of fluorescence responses in HEK-293 cells expressing h5- $\mathrm{HT}_{3 \mathrm{~A}}$ receptors to $30 \mu \mathrm{M} 5$-HT following incubation with the indicated concentration of vortioxetine using the membrane potential assay (see Materials and Methods). (F) Concentration-response curves for vortioxetine inhibition of h5-HT $\mathrm{HA}_{3 \mathrm{~A}}$ receptors at different concentrations of 5-HT. Data points represent the mean \pm S.D. from three individual experiments. (G) Concentration-inhibition curve for vortioxetine displacement of $\left[{ }^{3} \mathrm{H}\right]$ GR65630 binding at membranes isolated from HEK-293 cells expressing h5-HT $\mathrm{H}_{3 \mathrm{~A}}$ (see Materials and Methods). Data points represent mean \pm S.D. from at least three individual experiments. (H) Saturation analysis of $\left[{ }^{3} \mathrm{H}\right]$ vortioxetine binding at cell membranes isolated from HEK-293 cells expressing h5-HT 3 .

these mutations either disrupt receptor folding and assembly, surface expression, or function. In any case, the lack of activity in the membrane potential assay prevented characterization of the potential impact of the mutations on vortioxetine pharmacology. Therefore, these functionally inactive mutants were not studied further. Previous work has reported functional mutants of Asn123 (Ala and Asp) (Thompson et al., 2005) and Ser177 (Ala and Thr) (Thompson et al., 2005) in m5$\mathrm{HT}_{3 \mathrm{~A}}$, and Glu231 in both h5- $\mathrm{HT}_{3 \mathrm{~A}}$ and $\mathrm{m} 5-\mathrm{HT}_{3 \mathrm{~A}}$ (Gln, Asp, and Ala) (Schreiter et al., 2003; Thompson et al., 2005), whereas mutants of Asp64 have not previously been tested according to the best of our knowledge.

The remaining 10 mutants (covering five positions) were found to generate robust responses to 5 -HT stimulation that allowed for determination of 5-HT EC 50 (Table 4). Increases in 5-HT $\mathrm{EC}_{50}$ were observed for the V202A mutation and all substitutions at Thr176 and Asn123 (Table 4). These effects likely reflect that Thr176, Asn123, and V202A interact directly with 5-HT, and previous studies have observed similar shifts in 5-HT affinity upon mutations of Thr176 and Asn123 (Sullivan et al., 2006; Thompson et al., 2011). The remaining mutants displayed 5-HT $\mathrm{EC}_{50}$ within the 2-fold range of WT. We then determined vortioxetine $\mathrm{IC}_{50}$ at all functional binding site mutants (Fig. 7; Table 4). The mutations $\mathrm{T} 176 \mathrm{~V}$ and V202A significantly increased vortioxetine $\mathrm{IC}_{50}$ by 5 - and 11-fold, respectively, while the V202L mutation decreased the vortioxetine $\mathrm{IC}_{50}$ by 5 -fold (Fig. 8; Table 4 ). In contrast, all mutations of Ile66, Asn123, and Met223 produced less than 2-fold changes in vortioxetine $\mathrm{IC}_{50}$ (Fig. 8; Table 4). These results suggest key contributions of the side chains of Thr176 and Val202 to vortioxetine binding, and no or limited contributions from Ile66, Asn123, and Met223.

Correlation between Binding Modes and Mutant Effects. We used the data set from the mutational analysis as a final assessment of the potential of each binding mode cluster to represent the bioactive binding mode of vortioxetine 
A

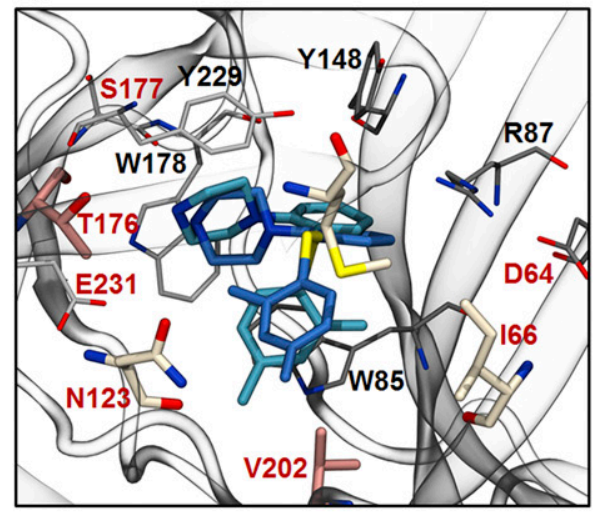

D

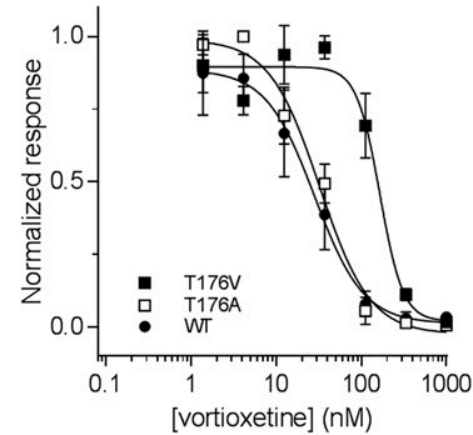

B

Ile66 (between loop D and F)

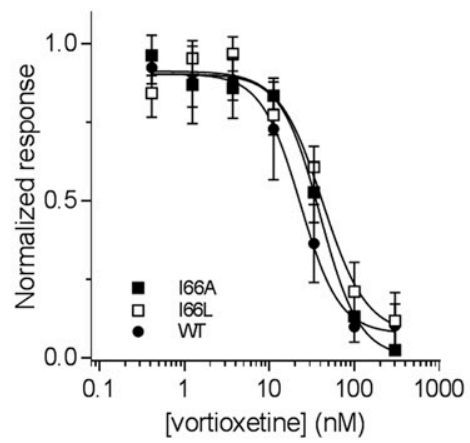

E

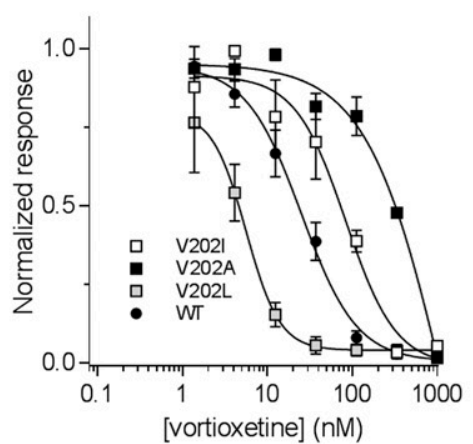

C

Asn123 (loop A)

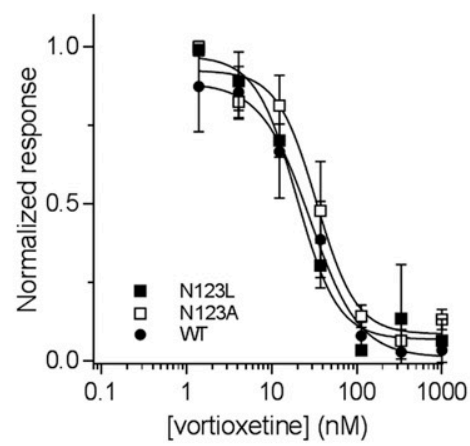

F $\quad$ Met223 (loop C)

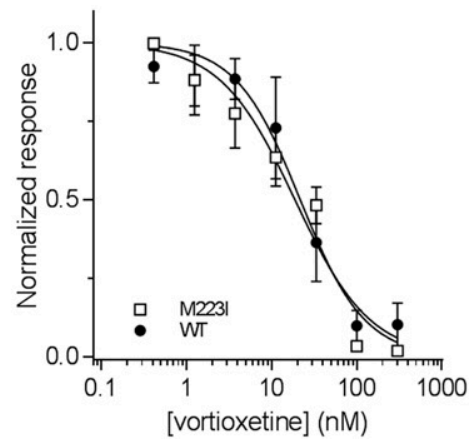

Fig. 7. Mutational analysis of vortioxetine binding. (A) Overview of key residues in the orthosteric binding site and vortioxetine orientation in the C11 (blue) and C13 (cyan) binding modes following short MD simulations. Mutated residues are labeled in red. Stick representations of residues where mutation resulted in decreased vortioxetine potency (Thr176 and Val202) are shown in pale red, and residues where mutation did not alter potency (Ile66, Asn123, and Met223) are shown in pale yellow. (B-F) Representative concentration-inhibition curves for point mutants at the indicated positions. Data points represent mean \pm S.D. from at least six individual concentration-response experiments for each mutant.

in the $\mathrm{h} 5-\mathrm{HT}_{3 \mathrm{~A}}$ receptor. The main observations that a bioactive binding mode should reconcile are: 1) gain or loss of potency upon change in bulk size of hydrophobic side chains of Val202 on loop F, 2) no or small effects upon change in bulk size of hydrophobic side chains at Ile66, and 3) 5-fold loss of potency upon removal of the side chain hydrophilicity of T176. Overall, the orientations and positions of vortioxetine in binding clusters $\mathrm{C} 2, \mathrm{C} 6$, and $\mathrm{C} 8$ do not fit well with two of these observations. First, in these binding modes the side chain of Val202 is located $>6 \AA$ from vortioxetine and displays no interactions with the ligand, which is inconsistent with the observations that vortioxetine potency is very sensitive to decrease (V202A) or subtle increase (V202L) in the bulk size of the side chain while maintaining hydrophobicity. Second, the $\mathrm{C} 2, \mathrm{C} 6$, and $\mathrm{C} 8$ binding modes predict phenyl A of vortioxetine to be located in a hydrophobic subpocket where it forms direct hydrophobic interactions with Ile66; an orientation that is inconsistent with the observed little or no effect of I66A and I66L mutations (Fig. 8).

The C11 binding mode overall fits well with the results from the mutational analysis. Vortioxetine is positioned sufficiently close to Val202 to form hydrophobic interactions with the side chain via phenyl $\mathrm{A}$, which agrees with the observed effects of decreased potency upon substitution with the smaller Ala by the V202A mutation. The side chain of Ile66 is not in direct contact with vortioxetine in the stabilized conformation found via MD simulations, thus being consistent with the lack of effect of the I66A and I66L mutations. The impact of the T176V mutation on vortioxetine potency is also compatible with this binding mode since $\mathrm{C} 11$ predicts the presence of a hydrogen bond between the ligand piperazine secondary amine and the Thr176 side chain hydroxyl group. T176V substitutes this hydroxyl for methyl and thus disrupts any hydrogen bond capacity of this side chain, which is consistent with the observed 6 -fold decrease in potency for the T176V mutant.

In C13, which was stable during the MD simulations, Val202 is making hydrophobic contacts to phenyl A and Ile66 is not in close contact with vortioxetine, which is thus consistent with the mutational results for these two residues. However, C13 predicts no ligand interaction with the side chain of Thr176 in the IFD data, in which the hydroxyl group is pointing away from the ligand. However, the MD simulations of $\mathrm{C} 13$ show that the side chain of Thr 176 reorients such that hydrogen bonds can form between the side chain hydroxyl and the secondary amine in the piperazine ring of vortioxetine, and loss of this interaction may underlie the effect of the T176V mutation.

In C30, the side chain of Ile66 is around $4 \AA$ from the piperazine ring, which is sufficiently distant to explain the lack of effect of Ile66 mutations that alter the bulk size of the side chain. However, Val202 is approximately $5 \AA$ away from the ligand, which is not compatible with the substantial effects of subtle changes in the bulk size of the side chain. 
TABLE 3

Rationale for mutagenesis of binding site residues and predicted impact of mutations on vortioxetine $\mathrm{IC}_{50}$ for binding mode clusters

\begin{tabular}{|c|c|c|c|c|c|}
\hline \multirow{2}{*}{ Residue } & \multirow{2}{*}{ Potential Binding Role of Side Chain ${ }^{a}$} & \multirow{2}{*}{ Cluster } & \multirow{2}{*}{ Mutation } & \multicolumn{2}{|c|}{ Predicted Effect ${ }^{a}$} \\
\hline & & & & Ligand Interaction & $\mathrm{IC}_{50}$ \\
\hline D64 & $\gamma$-COOH salt bridge with piperazine $\mathrm{NH}_{2}$ & $\mathrm{C} 30$ & $\mathrm{~V}$ & Disruption & $\uparrow \uparrow \uparrow$ \\
\hline $\mathrm{I} 66$ & Interactions with phenyl A & $\mathrm{C} 11, \mathrm{C} 13$ & $\mathrm{~A}$ & Disruption & $\uparrow$ \\
\hline I66 & Interactions with phenyl A & $\mathrm{C} 11, \mathrm{C} 13$ & $\mathrm{~L}$ & Minor effect & Minor effect \\
\hline N123 & $\gamma-\mathrm{NH}_{2}$ interaction with piperazine $\mathrm{NH}_{2}$ & $\mathrm{C} 8$ & $\mathrm{~A}$ & HB disruption & $\uparrow \uparrow$ \\
\hline N123 & $\gamma$ - $\mathrm{NH}_{2}$ interaction with piperazine $\mathrm{NH}_{2}$ & $\mathrm{C} 8$ & I & HB disruption & $\uparrow \uparrow$ \\
\hline N123 & $\gamma$ - $\mathrm{NH}_{2}$ interaction with piperazine $\mathrm{NH}_{2}$ & C8 & $\mathrm{L}$ & HB disruption & $\uparrow \uparrow$ \\
\hline N123 & Side chain close to phenyl B & $\mathrm{C} 2, \mathrm{C} 13$ & A & $\mathrm{HF}$ interaction & $\downarrow$ \\
\hline N123 & Side chain close to phenyl B & $\mathrm{C} 2, \mathrm{C} 13$ & I & $\mathrm{HF}$ interaction & $\downarrow$ \\
\hline N123 & Side chain close to phenyl B & $\mathrm{C} 2, \mathrm{C} 13$ & $\mathrm{~L}$ & $\mathrm{HF}$ interaction & $\downarrow$ \\
\hline T176 & $\gamma$-OH HB interaction with piperazine $\mathrm{NH}_{2}$ & $\mathrm{C} 8$ & $\mathrm{~A}$ & HB disruption & $\uparrow$ \\
\hline T176 & $\gamma$-OH HB interaction with piperazine $\mathrm{NH}_{2}$ & C8 & $\mathrm{V}$ & HB disruption & $\uparrow$ \\
\hline T176 & Transient $\gamma$-OH HB interaction with piperazine $\mathrm{NH}_{2}$ & $\mathrm{C} 11, \mathrm{C} 13$ & A & HB disruption & Minor effect \\
\hline T176 & Transient $\gamma$-OH HB interaction with piperazine $\mathrm{NH}_{2}$ & C11, C13 & $\mathrm{V}$ & HB disruption & Minor effect \\
\hline S177 & Side chain close to piperazine $\mathrm{NH}_{2}$ & $\mathrm{C} 2$ & $\mathrm{E}$ & HB formation & $\downarrow \downarrow$ \\
\hline V202 & Side chain distant from ligand & $\mathrm{C} 2, \mathrm{C} 6, \mathrm{C} 8$ & $\mathrm{~A}$ & No effect & No effect \\
\hline V202 & Side chain distant from ligand & $\mathrm{C} 2, \mathrm{C} 6, \mathrm{C} 8$ & I & No effect & No effect \\
\hline V202 & Side chain distant from ligand & $\mathrm{C} 2, \mathrm{C} 6, \mathrm{C} 8$ & $\mathrm{~L}$ & No effect & No effect \\
\hline V202 & Side chain close to phenyl A & C11, C13 & $\mathrm{A}$ & HF perturbation & $\uparrow$ \\
\hline V202 & Side chain close to phenyl A & C11, C13 & I & HF perturbation & Minor effect \\
\hline V202 & Side chain close to phenyl A & $\mathrm{C} 11, \mathrm{C} 13$ & $\mathrm{~L}$ & HF perturbation & Minor effect \\
\hline M223 & Side chain close to phenyl A & C30 & I & HF interaction & $\downarrow$ \\
\hline E231 & $\delta$ - $\mathrm{COOH}$ salt bridge with piperazine $\mathrm{NH}_{2}$ & C6 & I & Disruption & $\uparrow \uparrow \uparrow$ \\
\hline
\end{tabular}

${ }^{a} \mathrm{HB}$, hydrogen bond; $\mathrm{HF}$, hydrophobic interaction. Upwards arrow indicates predicted increase in $\mathrm{IC}_{50}$, downwards arrow indicates predicted decrease in $\mathrm{IC}_{50}$. Number of arrows indicates the predicted relative magnitude of the effect.

Moreover, on the opposite side of the binding pocket, the side chain of Thr176 is also more than $5 \AA$ away from the ligand, which cannot explain the T176V effect.

In summary, the binding modes of vortioxetine observed in the C2, C6, C8, and C30 docking clusters are not compatible with the results from the mutational analysis. Combined with the results of the MD simulations and binding energy analysis, we exclude these as potential bioactive binding modes. $\mathrm{C} 11$ and $\mathrm{C} 13$ display compatibility with all mutational observations when including data from both IFD calculations and MD simulations, and thus may represent bioactive conformations of vortioxetine in vivo. During the MD simulations of C11, vortioxetine assumed a conformation that is highly similar to the conformation in C13.
It is noteworthy that these binding modes then only differ by a $180^{\circ}$ rotation of phenyl A such that the ortho-methyl group is pointing in opposing directions. Thus, we suggest that C11 and C13 collectively represent the binding modes of vortioxetine in the $\mathrm{h} 5-\mathrm{HT}_{3 \mathrm{~A}}$ receptor in which vortioxetine binds with some flexibility since it can bind to the receptor with the aromatic ring A in two orientations.

\section{Discussion}

Our model of the vortioxetine binding mode at the h5- $\mathrm{HT}_{3 \mathrm{~A}}$ receptor provides insight into the molecular basis for the potentially unique mode of action of vortioxetine at the $5-\mathrm{HT}_{3}$

TABLE 4

5 -HT $\mathrm{EC}_{50}$ and vortioxetine $\mathrm{IC}_{50}$ values for $\mathrm{WT}$ and mutant $\mathrm{h} 5-\mathrm{HT}_{3 \mathrm{~A}}$ receptors

\begin{tabular}{|c|c|c|c|c|c|c|}
\hline \multirow{2}{*}{ Mutant } & \multicolumn{3}{|c|}{ 5-HT } & \multicolumn{3}{|c|}{ Vortioxetine } \\
\hline & $\mathrm{EC}_{50}{ }^{a}$ & $n^{b}$ & Fold Change & $\mathrm{IC}_{50}{ }^{a}$ & $n^{b}$ & Fold Change \\
\hline & $\mu M$ & & & $n M$ & & \\
\hline WT & $0.19[0.17 ; 0.21]$ & 33 & & $29[25 ; 34]$ & 9 & \\
\hline D64V & $\mathrm{NF}$ & 3 & & & & \\
\hline I66A & $0.32[0.24 ; 0.44]$ & 3 & $1.7[1.3 ; 2.3]$ & $52[41 ; 66]^{*}$ & 5 & $1.8[1.4 ; 2.3]$ \\
\hline I66L & $0.27[0.25 ; 0.29]$ & 3 & $1.4[1.3 ; 1.5]$ & $42[35 ; 50]^{*}$ & 5 & $1.4[1.2 ; 1.7]$ \\
\hline N123A & $1.8[1.5 ; 2.1]^{*}$ & 9 & $9.5[8.2 ; 11]$ & $47[40 ; 56]^{*}$ & 7 & $1.6[1.4 ; 1.9]$ \\
\hline N123I & $\mathrm{NF}$ & 3 & & & & \\
\hline N123L & $2.2[1.4 ; 3.4]^{*}$ & 4 & $12[7.6 ; 18]$ & $23[9 ; 57]$ & 3 & $0.8[0.3 ; 2.0]$ \\
\hline T176A & $2.2[2.0 ; 2.5]^{*}$ & 6 & $12[11 ; 13]$ & $32[28 ; 37]$ & 5 & $1.1[1.0 ; 1.3]$ \\
\hline $\mathrm{T} 176 \mathrm{~V}$ & $4.46[3.83 ; 5.19]^{*}$ & 7 & $23[20 ; 27]$ & $146[123 ; 174]^{*}$ & 5 & $5.0[4.2 ; 6.0]$ \\
\hline S177E & $\mathrm{NF}$ & 3 & & & & \\
\hline V202A & $6.16[5.53 ; 6.86]^{*}$ & 6 & $6.2[5.5 ; 6.9]$ & $310[252 ; 386]^{*}$ & 8 & $10.7[8.7 ; 13.3]$ \\
\hline V202I & $0.27[0.24 ; 0.31]$ & 4 & $0.27[0.24 ; 0.31]$ & $37[30 ; 45]$ & 7 & $1.3[1.0 ; 1.6]$ \\
\hline V202L & $0.05[0.03 ; 0.07]^{*}$ & 3 & $0.05[0.03 ; 0.07]$ & $5[4 ; 6]^{*}$ & 11 & $0.2[0.1 ; 0.2]$ \\
\hline M223I & $0.12[0.10 ; 0.13]$ & 3 & $0.12[0.10 ; 0.13]$ & $20[16 ; 25]$ & 5 & $0.7[0.6 ; 0.9]$ \\
\hline E231I & $\mathrm{NF}$ & 3 & & & & \\
\hline
\end{tabular}

${ }^{a} \mathrm{EC}_{50}$ and $\mathrm{IC}_{50}$ values were determined as described in Materials and Methods. Numbers in brackets denote the $95 \%$ confidence intervals.

${ }^{b} n$ denotes number of independent experiments.

$* P<0.01$ vs. WT. 

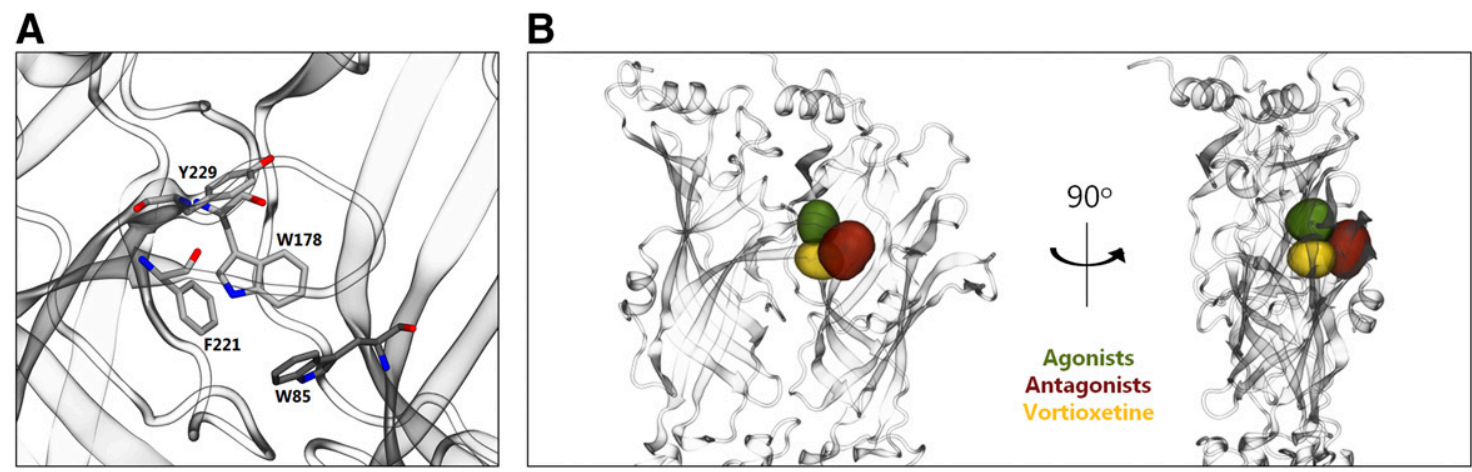

Fig. 8. Key features of the orthosteric binding site in $\mathrm{h} 5-\mathrm{HT}_{3 \mathrm{~A}}$. (A) Tube representation of the residues forming the aromatic box within the orthosteric binding site. All residues from the principal subunit are colored in white, while all residues from the complementary subunit are colored in gray. (B) Surface illustration of the subpockets involved in agonist (green), antagonist (red), and vortioxetine (yellow). The surrounding protein structure is shown as transparent ribbons.

receptor class. In the absence of a high-resolution structure of the $\mathrm{h} 5-\mathrm{HT}_{3 \mathrm{~A}}$ receptor, we used homology modeling to create a structural model of the receptor in an inactive state. Recently, structures of antagonist-bound eukaryotic pLGIC receptors have become available in the form of cryo-electron microscopy structures of a zebra fish GlyR (Du et al., 2015; Huang et al., 2015). Furthermore, a crystal structure of a desensitized nicotinic acetylcholine receptor (Morales-Perez et al., 2016) and a cryo-electron microscopy structure of a preactivated $\mathrm{m} 5-\mathrm{HT}_{3 \mathrm{~A}}$ receptor (Basak et al., 2018) have recently been published. In comparison with these structures, we find that the structures of the GlyR ECDs are very similar to our model. The single major difference is the structure of the $\mathrm{F}$ loop region that in our $\mathrm{h} 5-\mathrm{HT}_{3 \mathrm{~A}}$ model and the $\mathrm{m} 5-\mathrm{HT}_{3 \mathrm{~A}}$ crystal structure (Hassaine et al., 2014) contains a short $\alpha$-helical segment, which the GlyR structures do not. However, the Val202 residue important for vortioxetine binding is located in the $\mathrm{F}$ loop, outside the helical segment in a region where our model and GlyR are highly similar. Additionally, our h5- $\mathrm{HT}_{3 \mathrm{~A}}$ model is highly similar to the preactivated conformation of $\mathrm{m} 5-\mathrm{HT}_{3 \mathrm{~A}}$ (Basak et al., 2018). These observations suggest that our model is a good representative of the inactive conformation of the $\mathrm{h} 5-\mathrm{HT}_{3 \mathrm{~A}}$ receptor. In contrast, the conformation of $\mathrm{h} 5$ $\mathrm{HT}_{3 \mathrm{~A}}$ in our model is considerably less similar to the desensitized conformation of nicotinic acetylcholine receptors (Morales-Perez et al., 2016). Since vortioxetine produces a brief agonist response in $5-\mathrm{HT}_{3 \mathrm{~A}}$ followed by fast and prolonged desensitization, it is possible that vortioxetine binds with strongest affinity to the desensitized state. It would, therefore, be highly relevant in future work to investigate if our proposed vortioxetine binding mode is changed in the h5HT3 ${ }_{\mathrm{A}}$ model in the desensitized state. However, by the overall high degree of structural similarity to the preactivated $\mathrm{m} 5-\mathrm{HT}_{3 \mathrm{~A}}$, and in the ECD regions that harbor the orthosteric binding sites between our model and antagonist-bound GlyRs, we consider our present model a valid template for the ligand docking of vortioxetine.

Our ligand docking procedure yielded six possible binding modes of vortioxetine in the orthosteric binding site of the h5$\mathrm{HT}_{3 \mathrm{~A}}$ receptor. Following further assessment by MD simulations and binding free energy calculations, these six were narrowed down to three stable binding modes as candidates for the receptor-bound bioactive conformation of vortioxetine. We further evaluated these binding modes by mutagenesis of selected amino acid residues in the binding pocket. The observed effects of mutations on vortioxetine potency could only be fully reconciled with the highly similar $\mathrm{C} 11$ and $\mathrm{C} 13$ binding modes (Fig. 7). We, therefore, propose $\mathrm{C} 11$ and $\mathrm{C} 13$ as the bioactive binding modes. The resulting model of vortioxetine binding in the $\mathrm{h} 5-\mathrm{HT}_{3 \mathrm{~A}}$ receptor provides a framework to understand the molecular basis for the differential mechanism of action of vortioxetine at $5-\mathrm{HT}_{3 \mathrm{~A}}$ compared with other $5-\mathrm{HT}_{3}$ orthosteric ligands. As with other pLGICs, the h5- $\mathrm{HT}_{3 \mathrm{~A}}$ orthosteric binding pocket contains an aromatic box structural motif formed by Trp, Tyr, and Phe residues on loops A, B, C, and D (Fig. 8, Trp85, Phe221, Tyr229, and Trp178 in h5-HT 3 ) (Beene et al., 2002a,b; Xiu et al., 2009; Thompson et al., 2010). The role of these residues is extensively studied in the $5-\mathrm{HT}_{3}$ receptor (Beene et al., 2002a,b, 2004; Price et al., 2008), and multiple models exist for their role in binding of setrons and agonists. Early models, and more recently also X-ray structures of 5-HTBP in complex with setrons, collectively show three main factors necessary for setron binding and effect: 1) hydrogen bonds and cation $/ \pi$ interactions with Trp178 in the aromatic box (Kesters et al., 2013; Lochner and Thompson, 2016; Price et al., 2016); 2) cation $/ \pi$ and/or $\pi / \pi$ interactions with Tyr136, Tyr138, Tyr148, and Arg87 (Beene et al., 2004; Thompson et al., 2005, 2014; Yan and White, 2005; Joshi et al., 2006); and 3) setron occupation of a subsite beyond Arg87 near loops D and F (Fig. 8) (Kesters et al., 2013; Lochner and Thompson, 2016; Price et al., 2016). In our model, vortioxetine appears to interact with key motifs of the aromatic box in a similar manner, but also displays interactions that are distinct from setrons. A key similarity is the charged nitrogen on the piperazine ring, which is located in the center of the box and forms cation $/ \pi$ interactions to Trp178 and Tyr148 (Fig. 8). However, unlike setrons, vortioxetine does not interact with Tyr136, Tyr138, and Arg87 and does not occupy the subpocket beyond Arg87 (Fig. 8). Thus, the interaction pattern of vortioxetine is distinct from setrons.

In contrast to setrons, at saturating concentrations, vortioxetine also displays agonist activity at $5-\mathrm{HT}_{3 \mathrm{~A}}$. As for setrons, agonist binding has been shown to require hydrogen bonding and cation $/ \pi$ interactions with $\operatorname{Trp} 178$ (Beene et al., 2002b; Price et al., 2016), suggesting this interaction to be a common denominator for ligand binding in $5-\mathrm{HT}_{3}$ receptors. Unlike the setrons, however, agonists interact with the 5-HTBP equivalent of Tyr 148 within the complementary face and are not able 
to reach as far as Arg87 in loop D (Thompson et al., 2006a). Also, agonists interact with residues from loop $\mathrm{E}$ as well as loop D deep within the orthosteric binding pocket (Fig. 8B). Interestingly, in our model, vortioxetine does not interact with either of these two subsites but does interact with a subsite located at loop E closer to the membrane. This unique interaction pattern of vortioxetine could underlie its distinct functional profile. In this respect, it is interesting to note that previous studies have shown Trp85 from loop D (Spier and Lummis, 2000) as well as Tyr138 and Tyr148 from loop E (Beene et al., 2004; Price and Lummis, 2004) to be necessary to produce an agonist effect, and vortioxetine interacts extensively with both Trp85 and Tyr148 in our model.

The antidepressant effect of vortioxetine involves its highly potent inhibition of the serotonin transporter (Andersen et al., 2009; Bang-Andersen et al., 2011). We have previously reported a model of vortioxetine bound in a human serotonin transporter (hSERT) (Andersen et al., 2015). Key insights into the role of functional groups of vortioxetine in binding hSERT and $\mathrm{h} 5-\mathrm{HT}_{3 \mathrm{~A}}$ are of potential interest for future drug design of multimodal drugs targeting these serotonergic proteins. First, in both hSERT and h5$\mathrm{HT}_{3 \mathrm{~A}}$, the interactions of the positively charged nitrogen in the piperazine ring mimic the interactions with the primary amine of 5-HT. Specifically, the piperazine nitrogen forms an important salt bridge to Asp98 in hSERT, and makes hydrogen bond and cation $/ \pi$ interactions to Thr176 and Trp178, respectively, in $\mathrm{h} 5-\mathrm{HT}_{3 \mathrm{~A}}$. A contrasting feature is the overall role of the two phenyl rings of vortioxetine for binding at hSERT and h5-HT $3 \mathrm{~A}$. At h5-HT $3 \mathrm{~A}$, the phenyl rings make several $\pi / \pi$ and cation $/ \pi$ interactions, in particular to residues in the aromatic box, whereas in hSERT hydrophobicity of the phenyl rings rather than aromaticity is most important for binding (Andersen et al., 2015).

In summary, we have created and validated a model of the bioactive conformation of vortioxetine in the $\mathrm{h} 5-\mathrm{HT}_{3 \mathrm{~A}}$ receptor that provides new insight into the binding of a novel multimodal serotonergic drug. The binding pattern of vortioxetine mimics some aspects of both setron and 5-HT binding but also displays binding interactions not previously described to be important for binding of either setrons or 5-HT. Since the mechanism of vortioxetine differs from classic $5-\mathrm{HT}_{3 \mathrm{~A}}$ orthosteric ligands with inhibitory activity such as the setrons, our results may be an important first step toward understanding the molecular basis underlying the unique properties of vortioxetine. Specifically, this will include understanding the molecular determinants for how vortioxetine binding induces a brief agonistic response followed by a rapid transition into a desensitized state from which vortioxetine has an extremely slow unbinding rate. Finally, our results provide guidance in efforts to develop multimodal drugs with tailored activity across the spectrum of serotonergic proteins.

\section{Authorship Contributions}

Participated in research design: Ladefoged, Munro, Lummis, BangAndersen, Balle, Schiøtt, Kristensen.

Conducted experiments: Ladefoged, Munro, Pedersen.

Contributed new reagents or analytic tools: Lummis, BangAndersen.

Performed data analysis: Ladefoged, Munro, Kristensen.

Wrote or contributed to the writing of the manuscript: Ladefoged, Munro, Bang-Andersen, Balle, Schiøtt, Kristensen.

\section{References}

Alix K, Khatri S, Mosier PD, Casterlow S, Yan D, Nyce HL, White MM, Schulte MK, and Dukat M (2016) Superagonist, full agonist, partial agonist, and antagonist actions of arylguanidines at 5-hydroxytryptamine-3 $\left(5-\mathrm{HT}_{3}\right)$ subunit a receptors. ACS Chem Neurosci 7:1565-1574.

Althoff T, Hibbs RE, Banerjee S, and Gouaux E (2014) X-ray structures of GluCl in apo states reveal a gating mechanism of Cys-loop receptors. Nature 512:333-337.

Andersen J, Kristensen AS, Bang-Andersen B, and Strømgaard K (2009) Recent advances in the understanding of the interaction of antidepressant drugs with serotonin and norepinephrine transporters. Chem Commun (Camb) 25:3677-3692.

Andersen J, Ladefoged LK, Wang D, Kristensen TNB, Bang-Andersen B, Kristensen AS, Schiøtt B, and Strømgaard K (2015) Binding of the multimodal antidepressant drug vortioxetine to the human serotonin transporter. ACS Chem Neurosci 6: $1892-1900$

Andersen N, Corradi J, Sine SM, and Bouzat C (2013) Stoichiometry for activation of neuronal $\alpha 7$ nicotinic receptors. Proc Natl Acad Sci USA 110:20819-20824.

Baker NA, Sept D, Joseph S, Holst MJ, and McCammon JA (2001) Electrostatics of nanosystems: application to microtubules and the ribosome. Proc Natl Acad Sci USA 98:10037-10041.

Bang-Andersen B, Ruhland T, Jørgensen M, Smith G, Frederiksen K, Jensen KG, Zhong H, Nielsen SM, Hogg S, Mørk A, et al. (2011) Discovery of 1-[2-(2,4dimethylphenylsulfanyl)phenyl]piperazine ( $\mathrm{Lu}$ AA21004): a novel multimodal compound for the treatment of major depressive disorder. J Med Chem 54: 3206-3221.

Barnes NM, Hales TG, Lummis SC, and Peters JA (2009) The 5- $\mathrm{HT}_{3}$ receptor-the relationship between structure and function. Neuropharmacology 56:273-284.

Basak S, Gicheru Y, Samanta A, Molugu SK, Huang W, Fuente M, Hughes T, Taylor DJ, Nieman MT, Moiseenkova-Bell V, et al. (2018) Cryo-EM structure of 5-HT receptor in its resting conformation. Nat Commun 9:514.

Beene DL, Brandt GS, Lester HA, and Dougherty DA (2002a) Comparison of the cation- $\pi$ interaction at the agonist binding-sites of the nicotinic-acetylcholine receptor and the 5-hydroxytryptamine-3 receptor. Biophys $J$ 82:257a.

Beene DL, Brandt GS, Zhong W, Zacharias NM, Lester HA, and Dougherty DA (2002b) Cation- $\pi$ interactions in ligand recognition by serotonergic $\left(5-\mathrm{HT}_{3 \mathrm{~A}}\right)$ and nicotinic acetylcholine receptors: the anomalous binding properties of nicotine. Biochemistry 41:10262-10269.

Beene DL, Price KL, Lester HA, Dougherty DA, and Lummis SCR (2004) Tyrosine residues that control binding and gating in the 5-hydroxytryptamine $_{3}$ receptor revealed by unnatural amino acid mutagenesis. $J$ Neurosci 24:9097-9104.

Berger M, Gray JA, and Roth BL (2009) The expanded biology of serotonin. Annu Rev Med 60:355-366

Best RB, Zhu X, Shim J, Lopes PEM, Mittal J, Feig M, and Mackerell AD Jr (2012) Optimization of the additive CHARMM all-atom protein force field targeting improved sampling of the backbone $\phi, \psi$ and side-chain $\chi_{1}$ and $\chi_{2}$ dihedral angles. $J$ Chem Theory Comput 8:3257-3273.

Brady CA, Stanford IM, Ali I, Lin L, Williams JM, Dubin AE, Hope AG, and Barnes $\mathrm{NM}$ (2001) Pharmacological comparison of human homomeric 5- $\mathrm{HT}_{3 \mathrm{~A}}$ receptors versus heteromeric 5- $\mathrm{HT}_{3 \mathrm{~A} / 3 \mathrm{~B}}$ receptors. Neuropharmacology 41:282-284.

Brejc K, van Dijk WJ, Klaassen RV, Schuurmans M, van Der Oost J, Smit AB, and Sixma TK (2001) Crystal structure of an ACh-binding protein reveals the ligand-binding domain of nicotinic receptors. Nature 411:269-276.

Bulacu M, Goga N, Zhao W, Rossi G, Monticelli L, Periole X, Tieleman DP, and Marrink SJ (2013) Improved angle potentials for coarse-grained molecular dynamics simulations. J Chem Theory Comput 9:3282-3292.

Cheng Y and Prusoff WH (1973) Relationship between the inhibition constant $\left(K_{1}\right)$ and the concentration of inhibitor which causes 50 per cent inhibition $\left(I_{50}\right)$ of an enzymatic reaction. Biochem Pharmacol 22:3099-3108.

Corradi J, Gumilar F, and Bouzat C (2009) Single-channel kinetic analysis for activation and desensitization of homomeric $5-\mathrm{HT}_{3} \mathrm{~A}$ receptors. Biophys $J$ 97: $1335-1345$

daCosta CJB and Baenziger JE (2013) Gating of pentameric ligand-gated ion channels: structural insights and ambiguities. Structure 21:1271-1283.

Dale E, Grunnet M, Pehrson AL, Frederiksen K, Larsen PH, Nielsen J, Stensbøl TB, Ebert B, Yin H, Lu D, et al. (2018) The multimodal antidepressant vortioxetine may facilitate pyramidal cell firing by inhibition of $5-\mathrm{HT}_{3}$ receptor expressing interneurons: an in vitro study in rat hippocampus slices. Brain Res 1689:1-11.

de Jong DH, Singh G, Bennett WFD, Arnarez C, Wassenaar TA, Schäfer LV, Periole $\mathrm{X}$, Tieleman DP, and Marrink SJ (2013) Improved parameters for the Martini coarse-grained protein force field. J Chem Theory Comput 9:687-697.

Del Cadia M, De Rienzo F, Weston DA, Thompson AJ, Menziani MC, and Lummis SC (2013) Exploring a potential palonosetron allosteric binding site in the $5-\mathrm{HT}_{3}$ receptor. Bioorg Med Chem 21:7523-7528.

Du J, Lü W, Wu S, Cheng Y, and Gouaux E (2015) Glycine receptor mechanism elucidated by electron cryo-microscopy. Nature 526:224-229.

Fitch RW, Xiao Y, Kellar KJ, and Daly JW (2003) Membrane potential fluorescence: a rapid and highly sensitive assay for nicotinic receptor channel function. Proc Natl Acad Sci USA 100:4909-4914.

Friesner RA, Banks JL, Murphy RB, Halgren TA, Klicic JJ, Mainz DT, Repasky MP, Knoll EH, Shelley M, Perry JK, et al. (2004) Glide: a new approach for rapid, accurate docking and scoring. 1. Method and assessment of docking accuracy. J Med Chem 47:1739-1749.

Friesner RA, Murphy RB, Repasky MP, Frye LL, Greenwood JR, Halgren TA, Sanschagrin PC, and Mainz DT (2006) Extra precision glide: docking and scoring incorporating a model of hydrophobic enclosure for protein-ligand complexes. $J \mathrm{Med}$ Chem 49:6177-6196.

Genheden S and Ryde U (2015) The MM/PBSA and MM/GBSA methods to estimate ligand-binding affinities. Expert Opin Drug Discov 10:449-461.

Hassaine G, Deluz C, Grasso L, Wyss R, Tol MB, Hovius R, Graff A, Stahlberg H, Tomizaki T, Desmyter A, et al. (2014) X-ray structure of the mouse serotonin 5-HT receptor. Nature 512:276-281. 
Hibbs RE and Gouaux E (2011) Principles of activation and permeation in an anionselective Cys-loop receptor. Nature 474:54-60.

Homeyer N and Gohlke H (2012) Free energy calculations by the molecular mechanics Poisson-Boltzmann surface area method. Mol Inform 31:114-122.

Hope AG, Peters JA, Brown AM, Lambert JJ, and Blackburn TP (1996) Characterization of a human 5-hydroxytryptamine3 receptor type A (h5-HT3R-AS) subunit stably expressed in HEK 293 cells. Br J Pharmacol 118:1237-1245.

Huang X, Chen H, Michelsen K, Schneider S, and Shaffer PL (2015) Crystal structure of human glycine receptor- $\alpha 3$ bound to antagonist strychnine. Nature 526:277-280.

Huang X, Chen H, and Shaffer PL (2017) Crystal structures of human GlyR $\alpha 3$ bound to ivermectin. Structure 25:945-950.e2.

Jespersen T, Grunnet M, Angelo K, Klaerke DA, and Olesen SP (2002) Dual-function vector for protein expression in both mammalian cells and Xenopus laevis oocytes. Biotechniques 32:536-538, 540.

Jha A, Cadugan DJ, Purohit P, and Auerbach A (2007) Acetylcholine receptor gating at extracellular transmembrane domain interface: the Cys-loop and M2-M3 linker. J Gen Physiol 130:547-558.

Joshi PR, Suryanarayanan A, Hazai E, Schulte MK, Maksay G, and Bikádi Z (2006) Interactions of granisetron with an agonist-free $5-\mathrm{HT}_{3 \mathrm{~A}}$ receptor model. Biochemistry 45:1099-1105.

Joshi PR, Suryanarayanan A, and Schulte MK (2004) A vertical flow chamber for Xenopus oocyte electrophysiology and automated drug screening. $J$ Neurosci Methods 132:69-79.

Kesters D, Thompson AJ, Brams M, van Elk R, Spurny R, Geitmann M, Villalgordo JM, Guskov A, Danielson UH, Lummis SC, et al. (2013) Structural basis of ligand recognition in 5- $\mathrm{HT}_{3}$ receptors. EMBO Rep 14:49-56.

Klauda JB, Venable RM, Freites JA, O'Connor JW, Tobias DJ, Mondragon-Ramirez C, Vorobyov I, MacKerell AD Jr, and Pastor RW (2010) Update of the CHARMM all-atom additive force field for lipids: validation on six lipid types. $J$ Phys Chem $B$ 114:7830-7843.

Lochner M and Thompson AJ (2016) The muscarinic antagonists scopolamine and atropine are competitive antagonists at $5-\mathrm{HT}_{3}$ receptors. Neuropharmacology 108 : $220-228$.

Lummis SC (2012) 5- $\mathrm{HT}_{3}$ receptors. J Biol Chem 287:40239-40245.

Lummis SC and Thompson AJ (2013) Agonists and antagonists induce different palonosetron dissociation rates in $5-\mathrm{HT}_{3} \mathrm{~A}$ and $5-\mathrm{HT}_{3} \mathrm{AB}$ receptors. Neuropharmacology 73:241-246.

Lummis SC, Thompson AJ, Bencherif M, and Lester HA (2011) Varenicline is a potent agonist of the human 5-hydroxytryptamine3 receptor. $J$ Pharmacol Exp Ther 339:125-131.

Mahableshwarkar AR, Zajecka J, Jacobson W, Chen Y, and Keefe RS (2015) A randomized, placebo-controlled, active-reference, double-blind, flexible-dose study of the efficacy of vortioxetine on cognitive function in major depressive disorder. Neuropsychopharmacology 40:2025-2037.

Mähler J and Persson I (2012) A study of the hydration of the alkali metal ions in aqueous solution. Inorg Chem 51:425-438.

McIntyre RS, Florea I, Tonnoir B, Loft H, Lam RW, and Christensen MC (2017) Efficacy of vortioxetine on cognitive functioning in working patients with major depressive disorder. J Clin Psychiatry 78:115-121.

McIntyre RS, Lophaven S, and Olsen CK (2014) A randomized, double-blind, placebocontrolled study of vortioxetine on cognitive function in depressed adults. Int $J$ Neuropsychopharmacol 17:1557-1567.

Miller PS and Aricescu AR (2014) Crystal structure of a human GABA $_{\mathrm{A}}$ receptor. Nature 512:270-275.

Miller PS and Smart TG (2010) Binding, activation and modulation of Cys-loop receptors. Trends Pharmacol Sci 31:161-174.

Miyake A, Mochizuki S, Takemoto Y, and Akuzawa S (1995) Molecular cloning of human 5-hydroxytryptamine3 receptor: heterogeneity in distribution and function among species. Mol Pharmacol 48:407-416.

Morales-Perez CL, Noviello CM, and Hibbs RE (2016) X-ray structure of the human $\alpha 4 \beta 2$ nicotinic receptor. Nature 538:411-415.

Mørk A, Montezinho LP, Miller S, Trippodi-Murphy C, Plath N, Li Y, Gulinello M, and Sanchez C (2013) Vortioxetine (Lu AA21004), a novel multimodal antidepressant, enhances memory in rats. Pharmacol Biochem Behav 105:41-50.

Moura Barbosa AJ, De Rienzo F, Ramos MJ, and Menziani MC (2010) Computational analysis of ligand recognition sites of homo- and heteropentameric $5-\mathrm{HT}_{3}$ receptors. Eur J Med Chem 45:4746-4760.

Nemecz Á, Prevost MS, Menny A, and Corringer PJ (2016) Emerging molecular mechanisms of signal transduction in pentameric ligand-gated ion channels. Neuron 90:452-470.

Nys M, Kesters D, and Ulens C (2013) Structural insights into Cys-loop receptor function and ligand recognition. Biochem Pharmacol 86:1042-1053.

Paissoni C, Spiliotopoulos D, Musco G, and Spitaleri A (2015) GMXPBSA 2.1: a GROMACS tool to perform MM/PBSA and computational alanine scanning. Comput Phys Commun 186:105-107.

Poulsen MH, Lucas S, Bach TB, Barslund AF, Wenzler C, Jensen CB, Kristensen AS and Strømgaard K (2013) Structure-activity relationship studies of argiotoxins: selective and potent inhibitors of ionotropic glutamate receptors. J Med Chem $\mathbf{5 6}$ : $1171-1181$.

Price KL, Bower KS, Thompson AJ, Lester HA, Dougherty DA, and Lummis SCR (2008) A hydrogen bond in loop A is critical for the binding and function of the 5- $\mathrm{HT}_{3}$ receptor. Biochemistry 47:6370-6377.

Price KL, Lillestol RK, Ulens C, and Lummis SC (2015) Varenicline interactions at the $5-\mathrm{HT}_{3}$ receptor ligand binding site are revealed by 5 -HTBP. ACS Chem Neurosci 6:1151-1157.

Price KL, Lillestol RK, Ulens C, and Lummis SCR (2016) Palonosetron-5-HT 3 receptor interactions as shown by a binding protein cocrystal structure. ACS Chem Neurosci 7:1641-1646.
Price KL and Lummis SC (2005) FlexStation examination of 5- $\mathrm{HT}_{3}$ receptor function using $\mathrm{Ca}^{2+}$ - and membrane potential-sensitive dyes: advantages and potential problems. J Neurosci Methods 149:172-177.

Price KL and Lummis SCR (2004) The role of tyrosine residues in the extracellular domain of the 5-hydroxytryptamine ${ }_{3}$ receptor. J Biol Chem 279: 23294-23301.

Rayes D, De Rosa MJ, Sine SM, and Bouzat C (2009) Number and locations of agonist binding sites required to activate homomeric Cys-loop receptors. $J$ Neurosci 29: 6022-6032

Riga MS, Sánchez C, Celada P, and Artigas F (2016) Involvement of 5- $\mathrm{HT}_{3}$ receptors in the action of vortioxetine in rat brain: focus on glutamatergic and GABAergic neurotransmission. Neuropharmacology 108:73-81.

Robertson DW, Lacefield WB, Bloomquist W, Pfeifer W, Simon RL, and Cohen ML (1992) Zatosetron, a potent, selective, and long-acting 5HT3 receptor antagonist: synthesis and structure-activity relationships. $J$ Med Chem 35: $310-319$

Ruepp MD, Wei H, Leuenberger M, Lochner M, and Thompson AJ (2017) The binding orientations of structurally-related ligands can differ; a cautionary note. Neuropharmacology 119:48-61.

Sali A and Blundell TL (1993) Comparative protein modelling by satisfaction of spatial restraints. J Mol Biol 234:779-815.

Sanchez C, Asin KE, and Artigas F (2015) Vortioxetine, a novel antidepressant with multimodal activity: review of preclinical and clinical data. Pharmacol Ther 145: $43-57$.

Sander T, Bruun AT, and Balle T (2010) Docking to flexible nicotinic acetylcholine receptors: a validation study using the acetylcholine binding protein. J Mol Graph Model 29:415-424.

Sauguet L, Shahsavar A, and Delarue M (2015) Crystallographic studies of pharmacological sites in pentameric ligand-gated ion channels. Biochim Biophys Acta 1850:511-523.

Schreiter C, Hovius R, Costioli M, Pick H, Kellenberger S, Schild L, and Vogel H (2003) Characterization of the ligand-binding site of the serotonin $5-\mathrm{HT}_{3}$ receptor the role of glutamate residues 97, 224, and 235. J Biol Chem 278:22709-22716.

Sherman W, Day T, Jacobson MP, Friesner RA, and Farid R (2006) Novel procedure for modeling ligand/receptor induced fit effects. J Med Chem 49: $534-553$.

Smit AB, Syed NI, Schaap D, van Minnen J, Klumperman J, Kits KS, Lodder H, van der Schors RC, van Elk R, Sorgedrager B, et al. (2001) A glia-derived acetylcholinebinding protein that modulates synaptic transmission. Nature 411:261-268.

Spier AD and Lummis SCR (2000) The role of tryptophan residues in the 5-hydroxytryptamine ${ }_{3}$ receptor ligand binding domain. J Biol Chem 275 $5620-5625$

Sullivan NL, Thompson AJ, Price KL, and Lummis SC (2006) Defining the roles of Asn-128, Glu-129 and Phe-130 in loop A of the 5-HT 3 receptor. Mol Membr Biol 23: $442-451$

Thompson AJ, Duke RK, and Lummis SC (2011) Binding sites for bilobalide, diltiazem, ginkgolide, and picrotoxinin at the 5- $\mathrm{HT}_{3}$ receptor. $\mathrm{Mol}$ Pharmacol 80: 183-190.

Thompson AJ, Lester HA, and Lummis SCR (2010) The structural basis of function in Cys-loop receptors. Q Rev Biophys 43:449-499.

Thompson AJ, Padgett CL, and Lummis SCR (2006a) Mutagenesis and molecular modeling reveal the importance of the $5-\mathrm{HT}_{3}$ receptor F-loop. $J$ Biol Chem 281 : 16576-16582.

Thompson AJ, Price KL, Reeves DC, Chan SL, Chau PL, and Lummis SCR (2005) Locating an antagonist in the $5-\mathrm{HT}_{3}$ receptor binding site using modeling and radioligand binding. J Biol Chem 280:20476-20482.

Thompson AJ, Sullivan NL, and Lummis SC (2006b) Characterization of 5- $\mathrm{HT}_{3}$ receptor mutations identified in schizophrenic patients. J Mol Neurosci 30: 273-281.

Thompson AJ, Verheij MHP, Verbeek J, Windhorst AD, de Esch IJP, and Lummis SCR (2014) The binding characteristics and orientation of a novel radioligand with distinct properties at $5-\mathrm{HT}_{3} \mathrm{~A}$ and $5-\mathrm{HT}_{3} \mathrm{AB}$ receptors. Neuropharmacology 86 : 378-388.

Unwin N (2005) Refined structure of the nicotinic acetylcholine receptor at $4 \AA$ resolution. J Mol Biol 346:967-989.

Unwin N and Fujiyoshi Y (2012) Gating movement of acetylcholine receptor caught by plunge-freezing. J Mol Biol 422:617-634.

Wang J, Morin P, Wang W, and Kollman PA (2001) Use of MM-PBSA in reproducing the binding free energies to HIV-1 RT of TIBO derivatives and predicting the binding mode to HIV-1 RT of efavirenz by docking and MM-PBSA. J Am Chem Soc 123:5221-5230

Xiu X, Puskar NL, Shanata JA, Lester HA, and Dougherty DA (2009) Nicotine binding to brain receptors requires a strong cation- $\pi$ interaction. Nature 458 : $534-537$

Yan D and White MM (2005) Spatial orientation of the antagonist granisetron in the ligand-binding site of the 5- $\mathrm{HT}_{3}$ receptor. Mol Pharmacol 68:365-371.

Yang J (1990) Ion permeation through 5-hydroxytryptamine-gated channels in neuroblastoma N18 cells. J Gen Physiol 96:1177-1198.

Zuber B and Unwin N (2013) Structure and superorganization of acetylcholine receptor-rapsyn complexes. Proc Natl Acad Sci USA 110:10622-10627.

Address correspondence to: Birgit Schiøtt, Interdisciplinary Nanoscience Center (iNANO), Department of Chemistry, Aarhus University, Langelandsgade 140, DK-8000 Aarhus, Denmark. E-mail: birgit@chem.au.dk; or ${ }^{2}$ Anders S. Kristensen, Department of Drug Design and Pharmacology, University of Copenhagen, Universitetsparken 2, DK-2100 Copenhagen, Denmark. E-mail: ask@sund.ku.dk 